\title{
Future evolution of the Sahel precipitation zonal contrast in CESM1
}

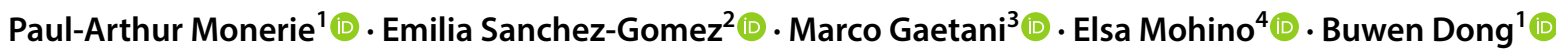

Received: 13 February 2020 / Accepted: 7 August 2020 / Published online: 17 August 2020

(c) The Author(s) 2020

\begin{abstract}
The main focus of this study is the zonal contrast of the Sahel precipitation shown in the CMIP5 climate projections: precipitation decreases over the western Sahel (i.e., Senegal and western Mali) and increases over the central Sahel (i.e., eastern Mali, Burkina Faso and Niger). This zonal contrast in future precipitation change is a robust model response to climate change but suffers from a lack of an explanation. To this aim, we study the impact of current and future climate change on Sahel precipitation by using the Large Ensemble of the Community Earth System Model version 1 (CESM1). In CESM1, global warming leads to a strengthening of the zonal contrast, as shown by the difference between the 2060-2099 period (under a high emission scenario) and the 1960-1999 period (under the historical forcing). The zonal contrast is associated with dynamic shifts in the atmospheric circulation. We show that, in absence of a forced response, that is, when only accounting for internal climate variability, the zonal contrast is associated with the Pacific and the tropical Atlantic oceans variability. However, future patterns in sea surface temperature (SST) anomalies are not necessary to explaining the projected strengthening of the zonal contrast. The mechanisms underlying the simulated changes are elucidated by analysing a set of CMIP5 idealised simulations. We show the increase in precipitation over the central Sahel to be mostly associated with the surface warming over northern Africa, which favour the displacement of the monsoon cell northwards. Over the western Sahel, the decrease in Sahel precipitation is associated with a southward shift of the monsoon circulation, and is mostly due to the warming of the SST. These two mechanisms allow explaining the zonal contrast in precipitation change.
\end{abstract}

Keywords Sahel zonal contrast $\cdot$ Sahel precipitation $\cdot$ Climate change $\cdot$ Internal climate variability $\cdot$ Large ensemble

\section{Introduction}

The third and fifth phases of the Climate Model Intercomparison Projects (CMIP; see Taylor et al. 2012) have allowed the analysis of a large variety of climate simulations. Results have highlighted that the impact of climate change on Sahel

Electronic supplementary material The online version of this article (https://doi.org/10.1007/s00382-020-05417-w) contains supplementary material, which is available to authorized users.

Paul-Arthur Monerie

pmonerie@gmail.com

1 National Centre for Atmospheric Science (NCAS), Department of Meteorology, University of Reading, Reading, UK

2 CECI, UMR 5318, CERFACS/CNRS, Toulouse, France

3 Scuola Universitaria Superiore IUSS, Pavia, Italy

4 Dpto. Física de la Tierra y Astrofísica, Facultad Ciencias Físicas, Universidad Complutense de Madrid, Ciudad Universitaria, Plaza Ciencias, 28040 Madrid, Spain precipitation, as a whole coherent region, is strongly modeldependent, ranging from a decrease to an increase in future precipitation (Druyan 2011; Monerie et al. 2016; Yan et al. 2018), hence leading to a rather low signal-to-noise ratio (Caminade and Terray 2010). Therefore, no robust conclusions were reached from climate projections in the fourth and fifth assessment reports (Solomon et al. 2007; Barros et al. 2014).

Yet, numerous studies have been devoted to understand and quantify the impact of climate change on Sahel precipitation. Several mechanisms have then been pointed out. First, it is commonly accepted that the increase in global mean surface temperature leads to an increase in specific humidity following the Clausius-Clapeyron relation, allowing an increase in moisture convergence over the Sahel (i.e., thermodynamic changes) (Held and Soden 2006; Giannini 2010; Kitoh et al. 2013). Second, the warming of the northern Hemisphere is associated with a northward displacement of the monsoon cell, and with an increase in Sahel precipitation (Haarsma et al. 2005; Skinner et al. 2012; Chadwick 
et al. 2019). Besides, the increase in greenhouse gas concentration and temperature is associated with an increase in evaporation (Biasutti 2013) and with changes in moist static energy gradients, which are key factors for the development of the monsoon circulation (Bordoni and Schneider 2008). Third, changes in Sahel precipitation have been associated with changes in sea surface temperature (SST). The warming of the global ocean heats the troposphere and imposes stability, which may decrease moisture transport and convection over land (Held et al. 2005; Caminade and Terray 2010; Giannini 2010; Biasutti 2013; Gaetani et al. 2017; Hill et al. 2018). Patterns in SST change, such as the cross-equatorial Atlantic temperature gradient (Hoerling et al. 2006) and the northern-hemispheric differential warming (Park et al. 2015) have been shown to be one of the causes of Sahel precipitation change and model uncertainties. Therefore, the effects of climate change on Sahel precipitation are the result of complex interactions.

Fontaine et al. (2011b) have shown that a robust pattern emerges over the Sahel in response to global warming, with the majority of CMIP3 climate projections showing an increase in central Sahel precipitation and a decrease in western Sahel precipitation. This has also been shown within the CMIP5 ensemble (Monerie et al. 2012, 2013, 2016; Biasutti 2013; Roehrig et al. 2013; James et al. 2015; Diallo et al. 2016; Gaetani et al. 2017; Akinsanola and Zhou 2018; Dunning et al. 2018) and the CMIP6 ensemble (Almazroui et al. 2020; Monerie et al. 2020). The multi-model ensemble also projects a modulation of the seasonal cycle of Sahel precipitation, with a decrease over the western Sahel occurring mainly during the early Sahel rainy season (i.e., May-JuneJuly-August) and an increase over the central Sahel occurring mainly during the last months of the Sahel rainy season (i.e., August-September-October) (Biasutti 2013; Seth et al. 2013; Monerie et al. 2016; Dunning et al. 2018).

The central/western Sahel zonal contrast is found to be robust in climate projections, because it is simulated by a majority of independent climate realizations, but appears paradoxical in a region that is, at first approximation, considered as homogeneous (Nicholson 2013). However, several studies have shown that the recent observed recovery in Sahel precipitation, which has followed the 1960s-80 s drought (Lebel and Ali 2009; Sanogo et al. 2015; Panthou et al. 2018), has a similar behaviour, i.e., stronger over the eastern than over the western Sahel (Lebel and Ali 2009; Panthou et al. 2018). It has also been suggested to correspond to an observed mode of climate variability, as highlighted by Nicholson and Palao (1993), who have defined two spatially consistent sub-domains, the Sahel and a West Coast domain.

The presence of this zonal contrast in the climate projections could have strong implications for Sahel populations because regionally-adapted policies would have to be done to respond to heterogeneous climate change across the Sahel. For instance, reginal climate models also simulate a zonal contrast in precipitation change at the end of the twentyfirst century, highlighting strong effects of climate change on extreme events, with strong local future modulations on the number of dry days and extreme precipitation events (Diallo et al. 2016; Akinsanola and Zhou 2019). However, the zonal contrast is, as highlighted by Panthou et al. (2018), not fully understood yet. In this study we aim at documenting and understanding the zonal contrast to help providing reliable and usable information to decision makers.

Based on previous studies, we raised several hypotheses that can explain an amplification of the zonal contrast in Sahel precipitation towards the end of the twenty-first century:

[1] Several authors have shown that Sahel precipitation anomalies are strongly associated with the magnitude and patterns of the SSTs anomalies (Folland et al. 1986; Palmer 1986; Rowell et al. 1992; Knight et al. 2006; Mohino et al. 2011a; Martin and Thorncroft 2014b). Warming of the SST and changes in SST anomaly patterns could thus be responsible for the zonal contrast in Sahel precipitation.

[2] The zonal contrast could be directly associated with the warming over land. The warming is associated with an increase in evaporation and with changes in moist static energy gradients over land, both having an impact on the monsoon circulation. Besides, a strengthened SHL may favour moisture divergence on its western edge (advecting the relatively dry northerlies) and moisture convergence on its eastern edge (strengthening the westerlies) (Roehrig et al. 2011; Lavaysse et al. 2016), then leading to the zonal contrast. However, Shekhar and Boos (2017) demonstrated that the focus has to be made on the shift of the SHL location, and that the impact of a deepened SHL on Sahel precipitation is unclear.

[3] The zonal contrast could arise from the competitive roles of increases in land surface temperature and changes in SST, combining both hypothesis [1] and [2]. Both can lead to opposite effects but can act together to shape Sahel precipitation changes, as shown in Biasutti (2013) and Gaetani et al. (2017).

[4] Finally the emergence of a strong zonal contrast could be an artefact due to the inability of climate models to simulate the West African monsoon dynamic, as proposed in James et al. (2015) for the western Sahel.

Our goal is to revisit these mechanisms to shed light on their roles on the zonal dipole in Sahel precipitation change. We investigate the evolution of the zonal contrast over both the 20th and the twenty-first century by using a climate model. We separate the total response into a forced 
response [i.e., the response of a climate model to external forcing like the Greenhouse Gases (GHGs)] and a variation that is associated with the internal climate variability, i.e., in absence of external forcing.

We thus explore the drivers of the zonal contrast with the presence and in the absence of the forced response. On that purpose we use the Large Ensemble of the Community Earth System Model (CESM) (Kay et al. 2015).

The structure of the paper is summarized as follows: Sect. 2 describes the simulations and the methodologies used. In Sect. 3, we revisit the different mechanisms explaining the establishment and evolution of a zonal contrast in Sahel precipitation. A discussion is given in Sect. 4 and a conclusion in Sect. 5.

\section{Data and methods}

\subsection{Data}

\subsubsection{CESM1}

We use the 40 members of the Community Earth System Model (CESM) of the Large Ensemble Project (LENS, Kay et al. 2015). The model is hereafter noted CESM1. CESM1 is a coupled climate model, which includes ocean, land, atmosphere and sea ice components. The atmospheric model is the Community Atmosphere Model (CAM5.2; Hurrell et al. 2013). The land surface component is the Community Land Model version 4 (Lawrence et al. 2011), the ocean model is the Parallel Ocean Program version 2 (Smith et al. 2010) and the sea ice component is the Community Ice Code version 4 (Hunke et al. 2010). All components were run at $\sim 1^{\circ}$ horizontal resolution (Kay et al. 2015). Each member shares the same radiative forcing scenario (historical evolution in GHG concentration, volcanic forcing and anthropogenic aerosols) for the period 1920-2005 and the Radiative Concentration Pathway 8.5 (hereafter noted RCP8.5) for the period 2006-2100. The RCP8.5 emission scenario describes a future trajectory in anthropogenic emissions eventually resulting in $8.5 \mathrm{~W} \mathrm{~m}^{-2}$ radiative forcing in 2100 (Meinshausen et al. 2011). To build the large ensemble, the 40 members only differ by their initial atmospheric conditions. Details of the simulations are found in Kay et al. (2015). Model's outputs are publicly and freely available on the NCAR website (www. cesm.ucar.edu/projects/community-projects/LENS/datasets.html). CESM1 simulates an increase in Sahel precipitation over the central Sahel and a decrease in precipitation over the western Sahel (Monerie et al. 2017) (and Fig. 1), as in the CMIP5 ensemble, and is therefore particularly suitable for this study.

\subsubsection{AMIP simulations}

The simulations of the Atmospheric Model Intercomparison Project (AMIP), within the CMIP5 exercise (Taylor et al. 2012), are also considered. The idealised AMIP experiments are complementary to the simulations of the CESM1 large ensemble, and are used to identify the effects of the heterogeneous global SST warming, to the homogeneous SST warming, and to the land warming only. In the AMIP experiments, the models have been run in an atmospheric-only configuration. For the reference simulation (hereafter noted amip), the atmosphere is forced by prescribing observed SST and sea ice conditions for the period 1979-2008, and by the observed evolution in the atmospheric composition (e.g., $\mathrm{CO}_{2}$ atmospheric composition and aerosol emission), and the land use and land cover changes. Three other AMIP-type simulations are analysed. In the amip4K, a uniform increase of $4 \mathrm{~K}$ is added to the global SST forcing; in the amipFuture simulation, an SST pattern of climate change is scaled to have a global mean increase of $+4 \mathrm{~K}$. The pattern is taken from the CMIP3 ensemble mean change in the $1 \% / \mathrm{yr} \mathrm{CO}_{2}$ increase experiments at quadrupling (Bony et al. 2011). In the amip4xCO2, there is a quadrupling of the $\mathrm{CO}_{2}$ atmospheric concentration with prescribed SST. All other boundary conditions remain the same as in the AMIP control simulation (i.e., amip). We used a set of 8 models whose outputs were available at the time of the study (MRI-CGCM3, IPSLCM5A-LR, IPSL-CM5B-LR, CNRM-CM5, HadGEM2-A, MIROC5, MPI-ESM-LR and MPI-ESM-MR).

\subsubsection{Observations}

To discuss the ability of CESM1 to simulate the zonal contrast in Sahel precipitation we use several observations. Observed precipitation data are given by the Global Precipitation Climatology Center (GPCC) version v7 (Schneider et al. 2014), available from 1901 to present on a $0.5^{\circ} \times 0.5^{\circ}$ longitude on a global grid. Data of the Climate Research Unit (CRU; version 4.01) allow a good estimation of continental rainfall at a $0.5^{\circ}$ horizontal resolution from 1901 to 2016 (Harris et al. 2014), Data from the University of Delaware (UDEL; version 4.01; Willmott et al. 2001) are at the $0.5^{\circ}$ horizontal resolution from 1901 to 2014 . The Precipitation Reconstruction over Land (PREC/L) is at the $1.0^{\circ}$ horizontal resolution and is available from 1948 to present (Chen et al. 2002). The twentieth century reanalysis is produced by assimilating only surface pressure observations of synoptic pressure, monthly sea surface temperature and sea ice distribution (Compo et al. 2006). The twentieth century reanalysis is available from 1851 to present and the ensemble mean of the 56 generated members is use to evaluate CESM1 simulations of the Sahel precipitation and teleconnections. For surface air temperature we use the Berkeley 
Fig. 1 CESM1 ensemble mean change in precipitation as obtained between the period 2060-2099 (under the RCP8.5 emission scenario) and the period 1960-1999 (under the historical emission scenario). Changes are given for a July-August-September and for monthly mean changes of $\mathbf{b}$ western and $\mathbf{c}$ central Sahel precipitation. On a stippling represents the grid-points where at least $80 \%$ of the models agree with the sign of the multi-model mean precipitation change. On $\mathbf{b}$ and $\mathbf{c}$ vertical orange lines indicate the ensemble member spread, as computed by 2 times the ensemble member standard error (i.e.,

$\frac{\text { ensemble-member }}{\sqrt{n}}$, with $n=40$ ).

Western Sahel is defined between $20^{\circ} \mathrm{W}$ and $5^{\circ} \mathrm{W}$, and $10^{\circ}-20^{\circ} \mathrm{N}$. Central Sahel is defined between $5^{\circ} \mathrm{W}$ and $20^{\circ} \mathrm{E}$ and $10^{\circ}-20^{\circ} \mathrm{N}$ [see the red box on panel (a)] (a)
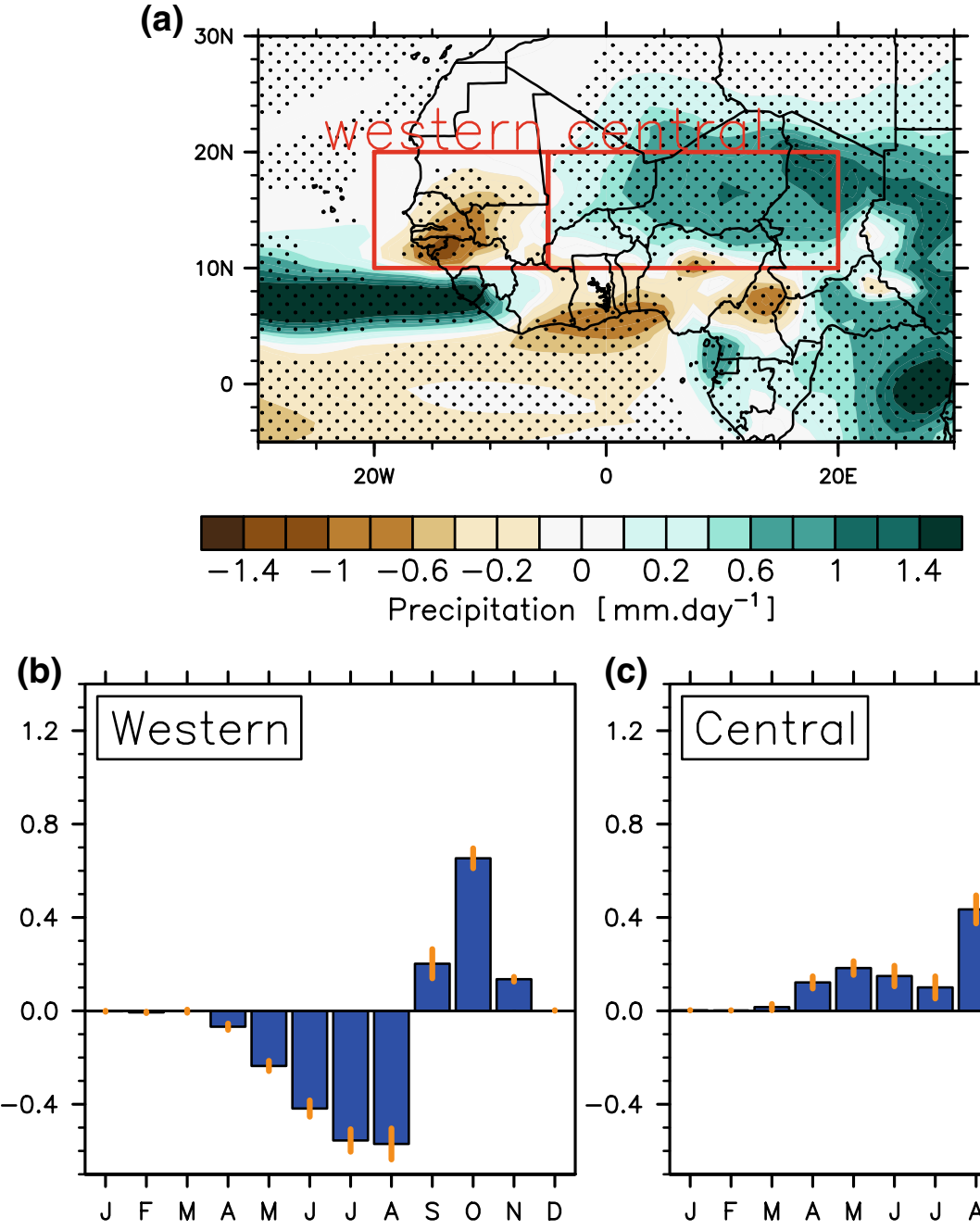

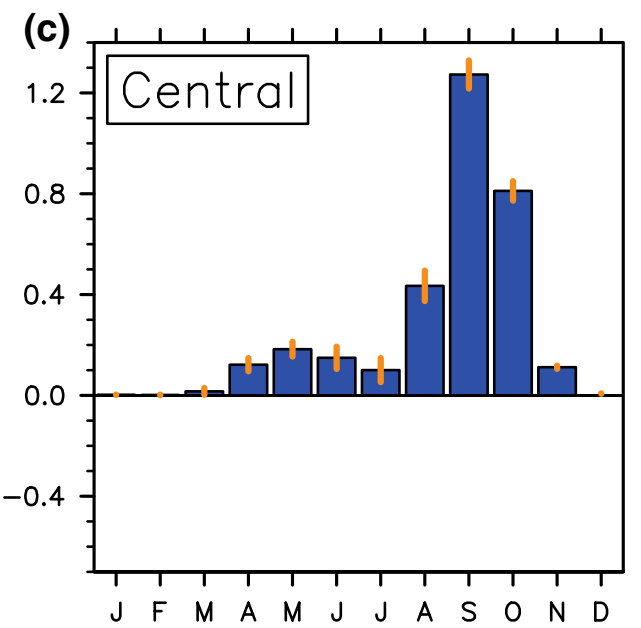

Earth Surface Temperature dataset (BEST), which is an interpolated dataset of surface air temperature anomalies (with respect to the period 1951-1980) over land and ocean built from temperature records by using statistical techniques (Rohde et al. 2013). These data are available from 1850 to present at a $1^{\circ} \times 1^{\circ}$ horizontal resolution.

\subsection{Methods}

\subsubsection{Estimating the forced response and internal climate variability}

A large ensemble (LENS) allows providing a broad statistical sampling of coupled internal climate variability (IV hereinafter). A climate model simulation can exhibit internal fluctuations of climate, but these oscillations are more likely to be out of phase among the 40 members, when not mostly driven by external forcing. The forced response can be defined as the common characteristic to all members of the ensemble. Hence, the forced response $\left(\overline{\Delta_{v}}\right)$ is estimated by the ensemble mean of the total response $\left(\Delta_{m v}\right)$ for a given variable $(v)$ by averaging over all members $(m)$ (Deser et al. 2014). Internal climate variability $\left(I V_{m v}\right)$ is obtained by subtracting the forced response from each individual member, i.e.,

$I V_{m v}=\Delta_{m v}-\overline{\Delta_{v}}$

We use the IV component to define how CESM1 simulates anomalies in a variable $v$, in absence of external forcing. We assess the impact of climate change using the ensemble mean.

\subsubsection{Decomposing precipitation change}

Held and Soden (2006) have shown that climate change leads to a general weakening of the tropical circulation, which they explained through decomposing tropical precipitation, by making the assumption that precipitation can be approximated by,

$\mathrm{P}=\mathrm{M}^{*} \mathrm{q}$

where $P$ is precipitation, $M^{*}$ is a proxy for convective massflux from the boundary layer to the free troposphere (with $M^{*}=P / q$ ) and $q$ is near surface specific humidity (see also 
Kent et al. 2015). Following Chadwick et al. (2016), changes in precipitation can then be decomposed, as

$\Delta \mathrm{P}=\Delta\left(\mathrm{M}^{*} \mathrm{q}\right)$

$\Delta \mathrm{P}=\mathrm{M}^{*} \Delta \mathrm{q}+\mathrm{q} \Delta \mathrm{M}^{*}+\Delta \mathrm{q} \Delta \mathrm{M}^{*}$

Precipitation change is then reformulated in terms of thermodynamic $\left(\Delta P_{\text {therm }}\right)$, dynamic $\left(\Delta P_{d y n}\right)$ and a cross nonlinear $\left(\Delta P_{\text {cross }}\right)$ components.

$\Delta \mathrm{P}=\Delta \mathrm{P}_{\text {therm }}+\Delta \mathrm{P}_{\text {dyn }}+\Delta \mathrm{P}_{\text {cross }}$

$\Delta P_{\text {therm }}$ is the thermodynamic component of $\Delta \mathrm{P}$, that is the change in precipitation associated with changes in specific humidity, at constant $M^{*} . \Delta P_{d y n}$ is the dynamic component and represents the contribution to $\Delta \mathrm{P}$ due to changes in circulation $\left(M^{*}\right)$ at constant $q . \Delta P_{\text {cross }}$ is the change in precipitation, explained by simultaneous changes in both circulation and specific humidity (Chadwick et al. 2013).

In a warmer climate, $q$ is expected to increase at approximately the Clausius-Clapeyron rate of $7 \% \mathrm{~K}^{-1}$ (see Held and Soden 2006), suggesting a strengthening of the contribution of the thermodynamic term for future climate conditions. However, precipitation increases at a weaker rate than specific humidity (Mitchell et al. 2007; Stephens and Ellis 2008; Chadwick et al. 2013) in climate models, due to a limited increase in tropospheric radiative cooling (Stephens and Ellis 2008), constraining the dynamic term to decrease with warming (i.e., $M^{*}=P / q$ ) (Held and Soden 2006; Vecchi and Soden 2007a; Chadwick et al. 2013). According to Vecchi and Soden (2007) the weakening of the tropical mean circulation is associated with less precipitation over land, globally, and with a strong shift of the circulation over the Pacific Ocean and in the Indian Ocean (not shown).

Further decomposition of $\Delta P_{d y n}$ allows to document changes that are due to the weakening of the tropical mean circulation $\left(\Delta P_{\text {weak }}\right)$ and to a shift in the pattern of the circulation $\left(\Delta P_{\text {shift }}\right)$, as

$\Delta \mathrm{P}_{\text {weak }}=q \Delta M_{\text {weak }}^{*}$

$\Delta \mathrm{P}_{\text {Shif }}=q \Delta M_{\text {Shif }}^{*}$

With,

$\Delta M_{\text {weak }}^{*}=-\alpha M^{*}$

where,

$\alpha=-\left(\right.$ tropical mean $\Delta M^{*} /$ tropical mean $M^{*}$ ).

$\alpha$ is scaled by the strength of the mean tropical circulation, suggesting that changes in the tropical mean circulation are inversely proportional to the climatology mass-flux field, as shown in Chadwick et al. (2013).
Finally,

$\Delta M_{\text {Shift }}^{*}=\Delta M^{*}-\Delta M_{\text {Weak }}^{*}$

The thermodynamic term can be partitioned into a component that corresponds to an increased maritime moisture advection onto land, and a residual that is associated with changes in circulation, evaporation and vertical mixing (Chadwick et al. 2016; Rowell and Chadwick 2018), by decomposing the change in near-surface specific humidity. A nonuniform circulation weakening could manifest itself through an increase in convection in some regions and a decrease in convection in other regions, and will be seen, through the decomposition, as a shift in the circulation. We made the assumption that this approximation is reasonable, although the interpretation of mechanisms would need to be reviewed.

The change in land specific humidity, with no change in circulation, and due to an increase in advection from the Ocean to land, in response to the change in specific humidity over the Ocean, is obtained by scaling historical mean moisture over land by the zonal mean fractional change in moisture over the Oceans (Chadwick et al. 2016).

$\mathrm{q}_{\text {land_future }}=\frac{\mathrm{q}_{\text {ocean_future }}}{\mathrm{q}_{\text {ocean_historical }}} \mathrm{q}_{\text {land_historical }}$

where, $\frac{q_{\text {ocean_future }}}{q_{\text {ocean_historical }}}$ is the zonal mean fractional change in moisture over the ocean, at the same latitude, with no change in the circulation. This approximation implies that changes in maritime advection mainly have a zonal source, as shown by Lélé et al. (2015). The change in moisture advection from the ocean onto land grid points is then obtained as,

$\Delta \mathrm{q}_{\text {adv }}=\mathrm{q}_{\text {land_future }}-\mathrm{q}_{\text {land_historical }}$

And the thermodynamic advection term is

$\Delta \mathrm{P}_{q a d v}=M^{*} \Delta q_{a d v}$

The residual thermodynamic is obtained as the change in precipitation associated with the change in specific humidity that is not due to the increase in maritime moisture advection $\left(\Delta q_{a d v}\right)$, over land, at constant dynamic, i.e.,

$\Delta \mathrm{q}_{\text {res }}=\Delta \mathrm{q}-\Delta \mathrm{q}_{a d v}$

And

$\Delta P_{\text {res }}=M^{*} \Delta q_{\text {res }}$

The decomposition is performed at the monthly time step (Chadwick et al. 2016; Rowell and Chadwick 2018) prior to compute the seasonal means and the area-weighted averages over a certain region. Changes in precipitation are evaluated by comparing precipitation of the period 2060-2099, 
under the RCP8.5 emission scenario, to the reference period 1960-1999, under the historical emission scenario. Timeevolutions of the anomalies are also assessed relative to the year 1920 . We used the $925 \mathrm{hPa}$ specific humidity for the decomposition because the 2-m specific humidity was only provided over the land areas in CESM1, but checked that over land this does not affect the results (focusing on $\Delta \mathrm{P}_{\text {therm }}, \Delta \mathrm{P}_{\text {dyn }}$ and $\Delta \mathrm{P}_{\text {cross }}$ ) (not shown).

\subsubsection{The African rainfall pattern index}

The African Rainfall Pattern Index (ARPI; Monerie et al., 2012) is a proxy of the zonal dipole and allows analysing the evolution of the Sahel precipitation zonal contrast. We first compute two Sahelian indices: the first is defined over the western Sahel (WS; $10^{\circ}-20^{\circ} \mathrm{N} ; 20^{\circ} \mathrm{W}-5^{\circ} \mathrm{W}$ ) and the second is defined over the central Sahel $\left(\mathrm{CS} ; 10^{\circ}-20^{\circ} \mathrm{N}\right.$; $\left.5^{\circ} \mathrm{W}-20^{\circ} \mathrm{E}\right)$.

$A R P I=\operatorname{stan}(\operatorname{stan}(C S)-\operatorname{stan}(W S))$

The central and western Sahelian indices are standardized (stan) to avoid western Sahel precipitation to dominate variations of the ARPI metric. In the standard ARPI, precipitations are averaged over the July-August-September (JAS) season.

\subsubsection{Computing the strength of the Saharan heat low}

We compute an index to account for the strength of the SHL. We followed Dixon et al. (2016) and compared Sahara $925 \mathrm{hPa}$ geopotential height $\left(Z G_{\text {Sahara }}\right)$ with tropical mean $\left(20^{\circ} \mathrm{S}-20^{\circ} \mathrm{N}\right) 925 \mathrm{hPa}$ geopotential height $\left(Z G_{\text {tropical_mean }}\right)$. As is Dunning et al. (2018) we compute the weighted area average over the Sahara between $15^{\circ} \mathrm{W}$ and $30^{\circ} \mathrm{E}$, and $20^{\circ} \mathrm{N}$ and $30^{\circ} \mathrm{N}$.

$\mathrm{SHL}=\mathrm{ZG}_{\text {Sahara }}-\mathrm{ZG}_{\text {tropical_mean }}$

We highlight that negative (positive) values of the index correspond to intense (weak) SHL. Using reanalysis datasets, Shekhar and Boos (2017) have shown that the impact of a strengthened SHL on the Sahel precipitation is unclear, whereas the effect of the meridional shift of the SHL is suggested to be robust. Therefore, we also analyse meridional shifts in the location of the SHL, by computing the zonal average of ZG-ZG $\mathrm{Z}_{\text {tropical_mean }}$, between $15^{\circ} \mathrm{W}$ and $30^{\circ} \mathrm{E}$, following Shekhar and Boos (2017). The location of the SHL is identified by selecting the latitude of the minimum value of ZG-ZG $\mathrm{Z}_{\text {tropical_mean }}$, after cubic splines interpolation.

In addition, we account for the 3D structure of the SHL by using another SHL definition, computing the difference between geopotential height at $700 \mathrm{hPa}$ and at $925 \mathrm{hPa}$ (i.e., $\mathrm{ZG}_{700}-\mathrm{ZG}_{925}$ ), averaged over the Sahara, hereafter called low-level atmospheric thickness (LLAT; Lavaysse et al. 2009), after Shekhar and Boos (2017).

\section{Results}

\subsection{Sahel precipitation forced response to global warming}

The spatial pattern of the precipitation change simulated by CESM1 is similar to the one of the CMIP5 multi-model ensemble-mean (Akinsanola and Zhou 2018; among others): an increase in precipitation over the central Sahel and a decrease in precipitation over the western Sahel at the end of the twenty-first century, relative to the end of the twentieth century (Fig. 1a). Over the central Sahel, both the increase in precipitation, north of $10^{\circ} \mathrm{N}$, and the decrease in precipitation, south of $10^{\circ} \mathrm{N}$, denote a northward shift of the West African monsoon. Over the western Sahel, monsoon precipitation tends to move southward. Although at a weaker intensity, similar changes have been obtained at a near-term time horizon (i.e., over the period 2010-2049) (Monerie et al., 2017) and with the RCP4.5 emission scenario (Monerie et al. 2012; Akinsanola and Zhou 2018), and the CMIP6 Shared Socioeconomic Pathways (Almazroui et al. 2020; Monerie et al. 2020).

It is worth noting that precipitation change simulated by CESM1 is particularly robust, as it is reproduced by most of the members (see the stippling on Fig. 1a). It has been argued that uncertainties in simulating tropical precipitation change at the end of the twenty-first century in CMIP5 models are mostly due to differences in climate models parameterizations rather than to internal climate variability (Hawkins and Sutton 2011). This would explain why the spread among the CESM1 members, is much reduced, in comparison to the multi-model CMIP5 ensemble spread, as also shown in Monerie et al. (2017).

In CESM1 the decrease in western Sahel precipitation is particularly strong from June to August (hereafter called JJA). The increase in central Sahel precipitation occurs at the end of the rainy season (August-October; hereafter called ASO) (Fig. 1b, c). These seasonal changes have also been shown within CMIP5 simulations (Biasutti 2013; Seth et al. 2013; among others), and have been associated with an anomalously late monsoon onset over the western Sahel and late monsoon cessation date over the central Sahel (Dunning et al. 2018). Therefore, we also assess impact of climate change on the longer JJASO period, and find similar results than for JAS, for both sign and magnitudes of precipitation change (Fig. S1). 


\subsection{Evolution of the Sahel zonal dipole}

To measure the evolution of the strength of the precipitation zonal contrast we compute the ARPI values following Eq. 15 (Sect. 2.2.3). Note that the definition of the central and western Sahel is slightly different from that in Monerie et al. (2012) to better account for the zonal precipitation contrast of CESM1. In addition, a refined index $\left(\mathrm{ARPI}_{\text {refined }}\right)$ has also been used, selecting two different seasons (i.e., JJA for the western Sahel and ASO for the central Sahel), instead of JAS for both areas, to better account for the temporal inhomogeneity. ARPI anomalies are computed relative to the year 1920 .

The ARPI ensemble mean shows that the zonal contrast is projected to strengthen in the future and in JAS, relative to the twentieth century (Fig. 2a), as shown within CMIP3 (Monerie et al. 2012) and CMIP5 (Biasutti 2013; among others) simulations. The forced ARPI variations are highly correlated with variations in global mean surface temperature with a correlation coefficient of 0.89 , suggesting that forced APRI variations might be explained through changes in global mean surface temperature. Besides, it is worth noting that impact of climate change emerges from internal climate variability after 1980, highlighting a strong impact of climate change on the zonal contrast (Fig. 2a grey shading).

The refined ARPI index shows a larger increase than the original ARPI index, maximizing the impacts of climate change on the zonal precipitation dipole. However, the time evolution of the refined index shows a very similar behaviour to that of the original ARPI. We thus focus on only the ARPI index, which can be more easily used than the refined ARPI index, with other models for which the timing in precipitation change could be different from that in CESM1. Results obtained with the refined index are presented in the supplementary material (Fig. S2).

\subsection{The ARPI index and internal climate variability}

We begin by exploring the hypothesis that the zonal dipole contrast could be caused by changes in SSTs in areas key for Sahel rainfall. Changes in SSTs in such areas would, in turn, be shaped by the forced response. Therefore, we show the SST-related factors controlling the zonal dipole in the absence of a forced response (i.e., the internal climate variability component of the ARPI index), before showing how the forced response could impact these factors.

We regress the time-series corresponding to the IV component of the ARPI time series onto the IV component of surface air temperature, over the ocean (Fig. 2b) [see equation (1)]. Note that for computing the ARPI-IV time-series the ensemble-mean shown in Fig. 2a is removed from the ensemble members and this results in time-series without a long temporal trend. The regression pattern obtained in
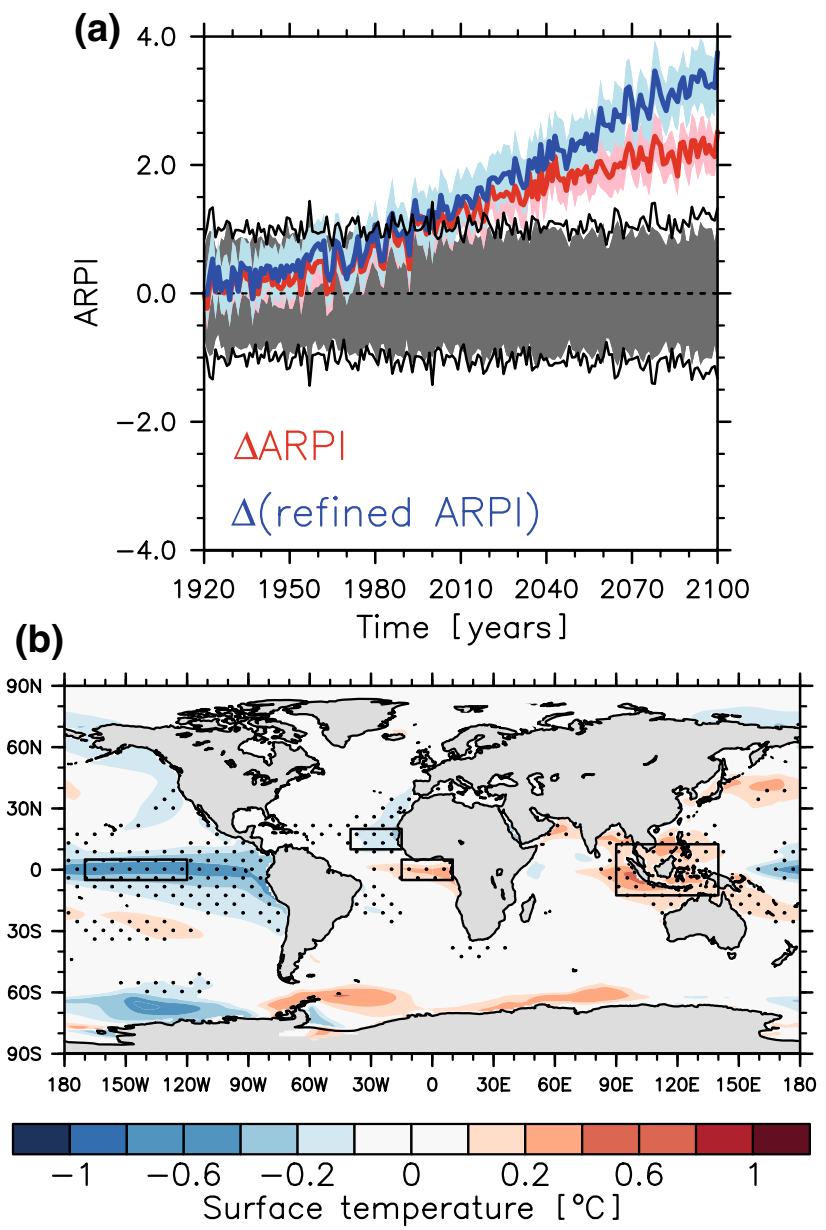

Fig. 2 a Ensemble mean ARPI (red; i.e., the difference between the standardized JAS central Sahel precipitation minus the JAS western Sahel precipitation) and refined ARPI (blue; i.e., the difference between the standardized ASO central Sahel precipitation minus the JJA western Sahel precipitation) change, relative to the year 1920. Blue and red shadings indicate the ensemble member spread, as defined by 2 times the standard error $\left(\frac{\text { ensemble-member }}{\sqrt{n}}\right.$, with $\left.n=40\right)$. Intermember spread in the internal variability component of ARPI (grey shading; i.e. obtained by inter-member standard deviation) and of the refined ARPI (black lines). b Ensemble-mean of internal component of ARPI regressed onto surface temperature internal variability, over the period 1920-2100, as first computed for each member. Stippling indicates that at least $80 \%$ of the members are simulating a regression that is significantly different to zero, according to a Spearman's rank test, at the $95 \%$ confidence level

Fig. $2 b$ i.e., a cooling over the eastern Pacific Ocean and warming over the maritime continent, is very similar to the negative phase of the El-Niño Southern Oscillation (ENSO) pattern in the tropical Pacific and suggests a possible contribution of ENSO in shaping the zonal dipole in the Sahel precipitation (Rowell et al. 1992; Joly et al. 2007; Fontaine et al. 2011a; Mohino et al. 2011b). In addition, the regression pattern also shows an Atlantic cross-equatorial gradient of SSTs, suggesting a role of this structure in the Sahel zonal contrast in the CESM1 model. To further understand the 
relationship between the Atlantic cross-equatorial SST gradient, ENSO, and Sahel precipitation, we analyse changes in precipitation associated with SSTs over the tropical Pacific and Atlantic oceanic basins in the next subsections, separately for the western and central Sahel. Firstly, we verified that ENSO and Atlantic cross-equatorial gradients are independent, with a correlation coefficient value of $r=-0.13$ between both indices. Secondly, we assess the relationship between western/central Sahel precipitation and surface temperature in the absence of external forcing (i.e., using the IV component), that is, how natural climate variability shapes the zonal dipole. This will help to elucidate how the external forcing could impact the Sahel zonal dipole via the SST-rainfall relationship.

\subsection{Western Sahel precipitation}

\subsubsection{Internal climate variability}

The internal component of western Sahel precipitation $\left(\mathrm{IV}_{\mathrm{pr}}\right)$ is regressed onto the internal component of ocean surface air temperature ( $\left.\mathrm{IV}_{\text {tas }}\right)$ over the long period 1920-2100 for each member individually. Changes in precipitation are strong in June-July-August (JJA) (Fig. 1c) so we analysed western Sahel precipitation over the JJA period in this section. The average of the 40 regression patterns is displayed in Fig. 3a [see equation (1)]. Results reveal an important role of the Atlantic cross-equatorial temperature gradient on the western Sahel precipitation IV component $\left(\mathrm{IV}_{\mathrm{pr}}\right.$; Fig. 3a). We only found significant correlations over the Atlantic Ocean, showing that the Atlantic cross-equatorial temperature gradient is key for the western Sahel (Fig. S3). The Tropical South Atlantic/Tropical North Atlantic (hereafter noted TSA/TNA) gradient is computed through the difference between the area-weighted temperature average over the TSA and TNA regions (see boxes on Fig. 3a). The regression of the IV component of the TSA/TNA gradient onto the IV component of the precipitation field highlights the connection between the tropical Atlantic Ocean and the meridional migration of the monsoon precipitation (Fig. 3b). This is consistent with the known observed modes of variability, for which an anomalously warm eastern equatorial Atlantic Ocean (or Gulf of Guinea) is associated with a decrease in Sahel precipitation (Nicholson 2005; Joly et al. 2007; Losada et al. 2012; Fontaine et al. 2011a). Analysis also reveals that the TSA/TNA impact is mostly mediated by changes in atmospheric circulation $\left(\Delta P_{d y n}\right)$ (Fig. 3c), while changes in the thermodynamic component are much more moderate (Fig. S4).

This analysis is repeated by using the raw western Sahel precipitation (i.e., internal + forced components) indices and the raw fields of surface temperature, which also shows a strong impact of the cross-equatorial Atlantic temperature gradient on western Sahel precipitation, over the historical period 1920-2005 (Fig. 3a). This suggest that the TSA/ TNA gradient could have a role in the total response of the zonal precipitation contrast over the Sahel, with the forced response driving changes in the TSA/TNA gradient. This will be addressed in the following section.

\subsubsection{Evolution of the tropical Atlantic thermal gradient}

Changes in precipitation can be strongly impacted by changes in the patterns of the SSTs. For instance, Hoerling et al. (2006) have shown that long-term changes in the temperature contrast, between the North and the South Atlantic gradient, can lead to changes in Sahel precipitation. An increase in the TSA/TNA temperature gradient, due to global warming, could then lead to long-term changes in western Sahel precipitation.

In JJA, the TSA/TNA gradient increases strongly over the 1920-2000 period (Fig. 3d). The positive trend is statistically different to zero according to a Spearman's rank correlation test (at the 95\% confidence level). Over the 1920-2000 period, western Sahel precipitation decreases with time (Fig. 4a), in agreement with a strengthening of the TSA/TNA gradient. This suggests that the cross-equatorial Atlantic gradient is one of the drivers of the ARPI evolution over the twentieth century.

Impact of climate change on the TSA/TNA thermal gradient is unclear, and the gradient is not stronger over the 2060-2099 period than over the 1960-1999 period. Unlike the TSA/TNA thermal gradient, western precipitation decreases over the twenty-first century, showing that the TSA/TNA thermal gradient is unlikely to be one of the main causes of the projected strengthening of the zonal contrast.

\subsection{Central Sahel precipitation}

\subsubsection{Internal climate variability}

We regress the internal component of central Sahel precipitation $\left(\mathrm{IV}_{\mathrm{pr}}\right)$ onto the internal component of ocean surface air temperature ( $\mathrm{IV}_{\text {tas }}$ ) over the long period 1920-2100. As changes in central Sahel precipitation are stronger in August-September-October (ASO) than throughout the year (Fig. 1c), we focus the analysis on the change in central Sahel precipitation on the ASO period. ASO central Sahel precipitation is strongly related to ENSO in CESM1 (Fig. 5a), highlighting the strong impact of the Tropical Pacific Ocean on the Sahel precipitation zonal contrast in this model. A zonal dipole appears between the eastern Pacific Ocean (i.e., Niño3.4 box) and the SSTs around the maritime continent (MAR hereinafter). We document ENSO evolution over the twentieth and twenty-first century by computing the difference between the Niño3.4 and 
(a)
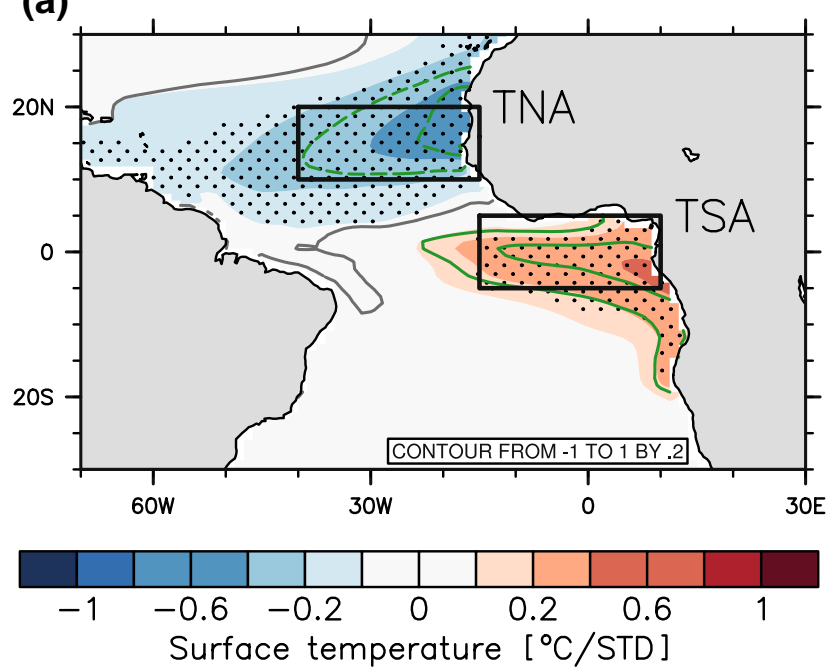

(c)

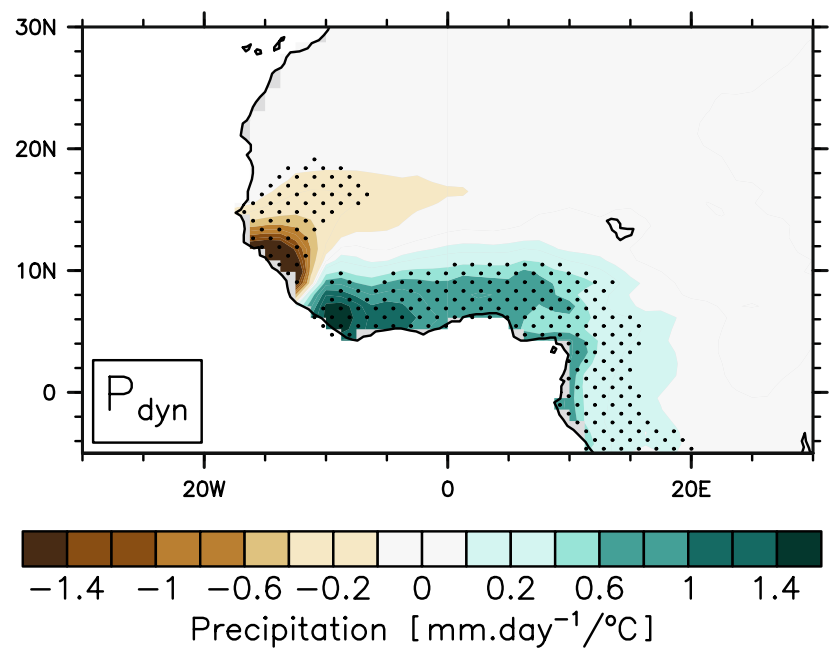

Fig. 3 a Ensemble mean of the surface temperature regressed onto the standardized western Sahel precipitation $\left({ }^{\circ} \mathrm{C} / \mathrm{STD}\right)$ in JJA over the historical period 1920-2005 for the raw data (green contours) and over the period 1920-2100 for the internal variability component of both precipitation and surface temperature (shading), as first computed for each member. Ensemble mean of $\mathbf{b}$ internal component of precipitation $\left(\mathrm{mm} \cdot \mathrm{day}^{-1} /{ }^{\circ} \mathrm{C}\right)$ and $\mathbf{c}$ internal component of $\Delta P_{d v n}(\mathrm{~mm}$. day ${ }^{-1} /{ }^{\circ} \mathrm{C}$ ) regressed onto the internal component of the TNA/TSA temperature gradient, as first computed for each member. Stippling indicates that at least $80 \%$ of the members are simulating a regression

MAR indices, and we estimate the impact of the ENSO by regressing the internal component variability of the Pacific zonal temperature gradient onto the internal component variability of the precipitation. The regression pattern shows that a negative (positive) ENSO phase is associated with a precipitation increase (decrease) over the central Sahel (Fig. 5b). ENSO is thus able to force a shift of the (b)
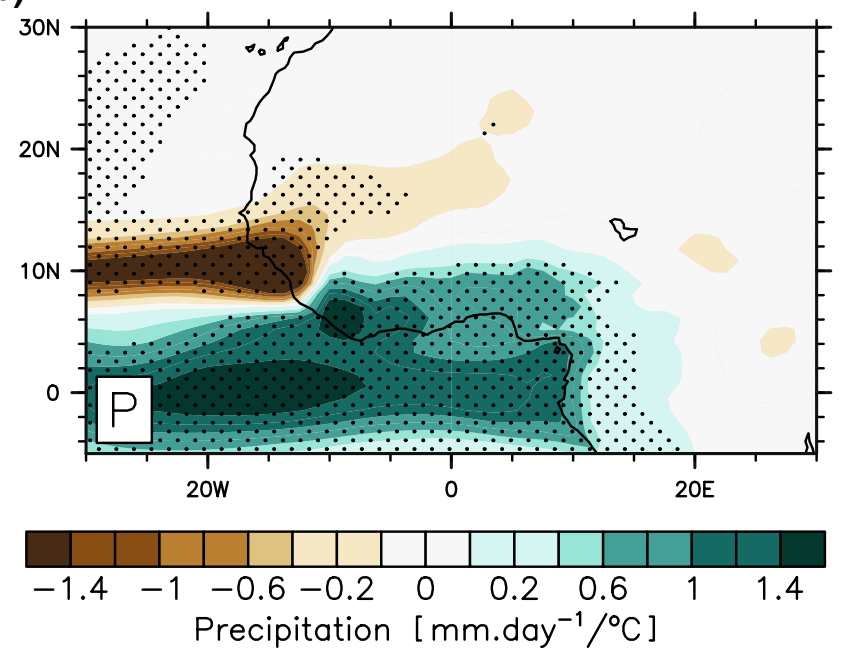

(d)

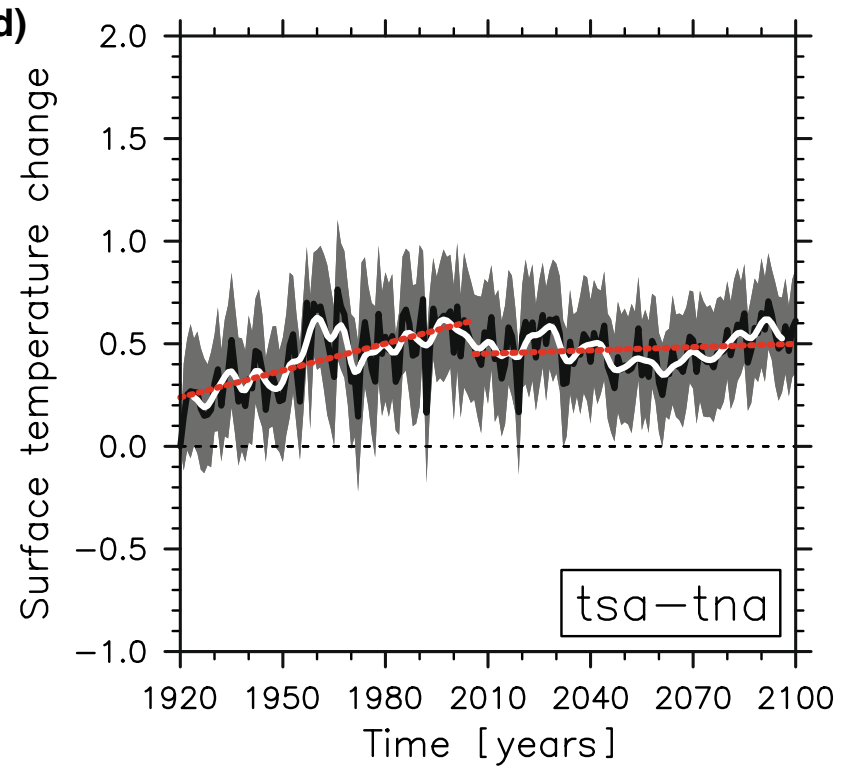

that is significantly different to zero, according to a Spearman's rank test, at the $95 \%$ confidence level. d Evolution of the ensemble-mean Tropical South Atlantic-Tropical North Atlantic temperature $\left({ }^{\circ} \mathrm{C}\right)$ in JJA [TSA/TNA; black line; see the black boxes on panel (a)], relative to the year 1920. The low-frequency evolution of the TSA/TNA gradient is obtained with a Lanczos filter (19 weights with a 9- year cutoff period; white line). Red lines indicate linear regressions over both 1920-2005 and 2006-2100 periods and the grey shading indicates the ensemble member spread, as defined by 2 times the standard error $\left(\frac{\text { ensemble-member }}{\sqrt{n}}\right.$, with $\left.n=40\right)$

rain belt over Africa between $0^{\circ}$ and $30^{\circ} \mathrm{E}$. The impact of the Tropical Pacific Ocean is mostly mediated by changes in atmospheric dynamic (Fig. 5c) rather than changes in the thermodynamic (Fig. S5). The analysis performed by computing the regression between the en 3.4 index and Sahel precipitation yields the same pattern as in Fig. 5b (not shown), showing that the EN34-MAR difference 
(a)

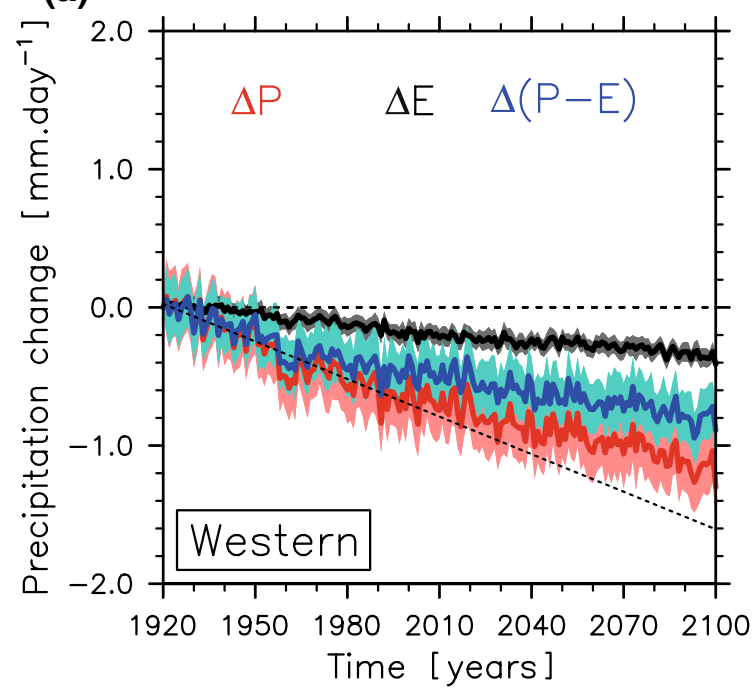

Fig. 4 Ensemble mean change in precipitation $(\Delta \mathrm{P}$; red), evaporation $(\Delta \mathrm{E}$; black) and moisture flux convergence $(\Delta(\mathrm{P}-\mathrm{E})$; blue $)$, relative to the year 1920 , for a JJA western Sahel precipitation and b ASO cen-

provides a robust estimate of the impacts of ENSO over Sahel precipitation.

Similar results are obtained with the raw time series over the historical period (green contour in Fig. 5a), so in the following we explore the role of the EN34/MAR gradient in the forced response.

\subsubsection{Evolution of the tropical Pacific thermal gradient}

The EN34/MAR gradient is projected to increase with time (Fig. 5d) in ASO. As a consequence, the impact of the Pacific thermal gradient on central Sahel precipitation increases over the $20^{\text {th }}$ and the twenty-first century. However, our results indicate that the impact of the Pacific thermal gradient in CESM1 is moderate on central Sahel precipitation and does not impact western Sahel precipitation (Fig. 5b). Moreover, central Sahel precipitation is projected to increase (Figs. 1c and 4b) while a strengthening of the EN34/MAR gradient leads to a decrease in central Sahel precipitation, showing that this thermal gradient is unlikely to explain the projected changes in central Sahel precipitation.

\subsubsection{Decomposing changes in Sahel precipitation}

We have shown that, when not influenced by the anthropogenic forcing, the Sahel zonal contrast is associated with SST patterns of natural climate variability. However, results shown in the previous sections suggest that the long-term change in the Sahel zonal contrast cannot be explained by long-term changes in surface temperature patterns over the ocean, as defined in Figs. $2 \mathrm{~b}$ and $3 \mathrm{~b}$ i.e. the long-term (b)

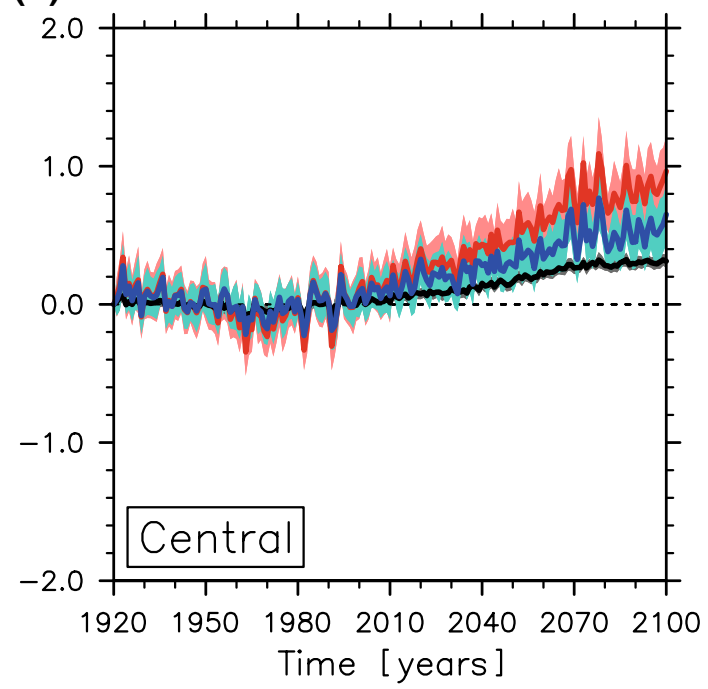

tral Sahel precipitation. The ensemble member spread (colour shadings) is defined by 2 times the standard error (i.e., $\frac{\text { ensemble-member }}{\sqrt{n}}$, with $\left.n=40\right)$.

changes in the TSA/TNA and EN34/MAR temperature gradients. Therefore, we take a step forward at better understanding the zonal contrast in this section by decomposing the changes in Sahel precipitation (Sect. 2).

\subsubsection{Western Sahel precipitation change}

Over the western Sahel, precipitation decreases continuously from 1920 to 2100 (Fig. 4a). It is worth noting that the decrease in precipitation is occurring at different rates, slower during the twenty-first century than during the twentieth century (see the dotted line in Fig. 4a). In spite of the local increase in surface air temperature (Fig. S6), evaporation decreases over the western Sahel. This is mostly due to the fact that, in the semi-arid region, changes in evaporation mostly depend on the changes in soil moisture, rather than in temperature (Cook et al. 2014). The change in moisture flux convergence also undergoes a slight decrease in its changing rate, weaker during the 21 st than during the twentieth century. Moreover, the moisture flux convergence change is stronger than the local precipitation recycling change, showing that the decrease in precipitation is mostly due to a decrease in moisture transport by the trade winds. Changes in moisture flux can be due to either or both changes in moisture air content and atmospheric circulation. Therefore, we decompose precipitation change into its dynamic, thermodynamic and cross nonlinear components.

By using the precipitation decomposition described in Sect. 2, we show that over the western Sahel the decrease in precipitation is mostly associated with the $\Delta P_{d y n}$ component (Fig. 6a), i.e., dynamic changes. The early decrease 
(a)
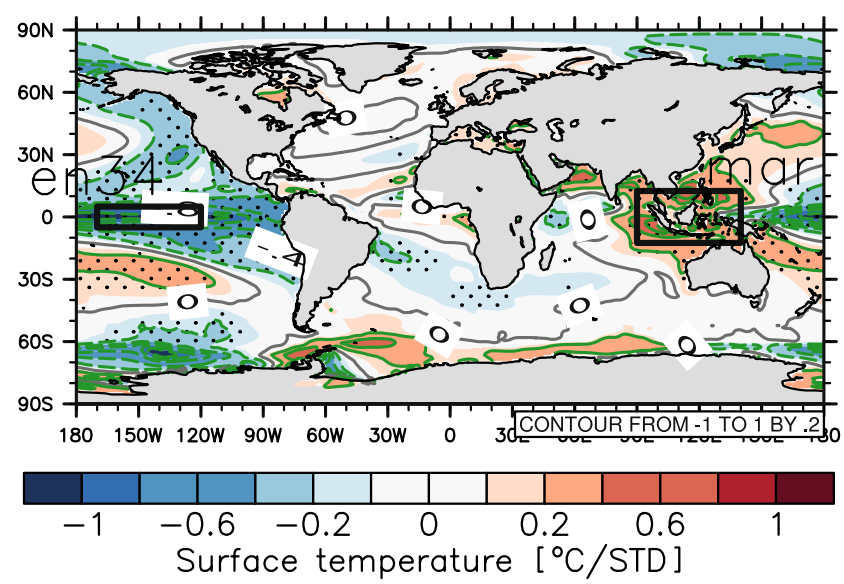

(c)
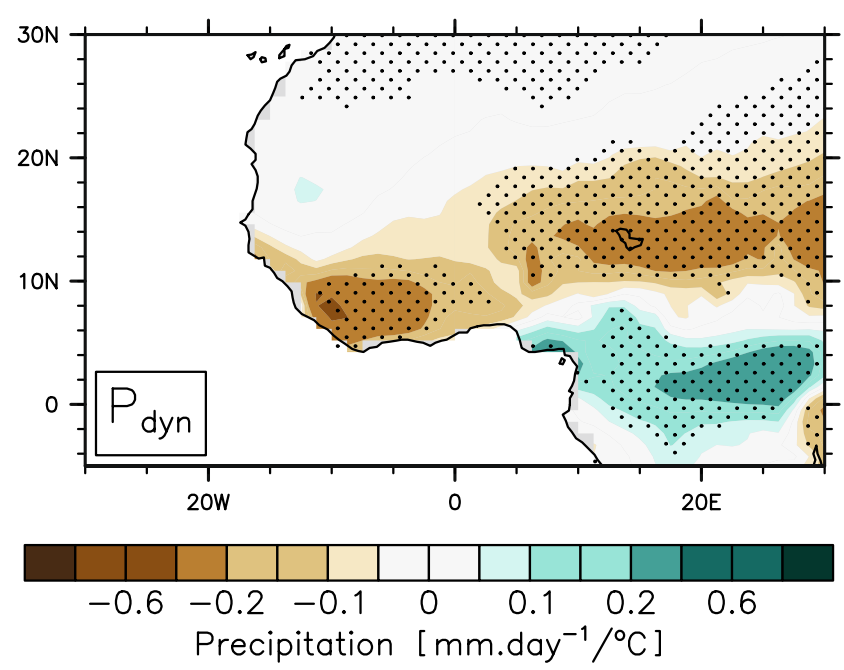

Fig. 5 a Ensemble mean of the surface temperature regressed onto the standardized central Sahel precipitation $\left({ }^{\circ} \mathrm{C} / \mathrm{STD}\right)$ in ASO over the historical period 1920-2005 for the raw data (green contours) and over the period 1920-2100 for the internal variability component of both precipitation and surface temperature (shading), as first computed for each member. Ensemble mean of the $\mathbf{b}$ internal component of precipitation $\left(\mathrm{mm} \cdot \mathrm{day}^{-1} /{ }^{\circ} \mathrm{C}\right.$ ) and $\mathbf{c}$ internal component of $\Delta P_{d y n}$ (mm.day ${ }^{-1} /{ }^{\circ} \mathrm{C}$ ) regressed onto the internal component of the EN34/ MAR temperature gradient, as first computed for each member. Stippling indicates that at least $80 \%$ of the members are simulating a

in $\Delta \mathrm{P}$ is only due to changes in $\Delta P_{d y n}$ while $\Delta P_{\text {therm }}$ and $\Delta P_{\text {cross }}$ impacts are only distinguishable during the twentyfirst century (Fig. 6a). Over the western Sahel the decrease in $\Delta P_{d y n}$ is linear through time and the change in the $\Delta$ $\mathrm{P}$ rate is explained by $\Delta P_{\text {therm }}$ that allows damping the decrease in precipitation, over the twenty-first century. (b)

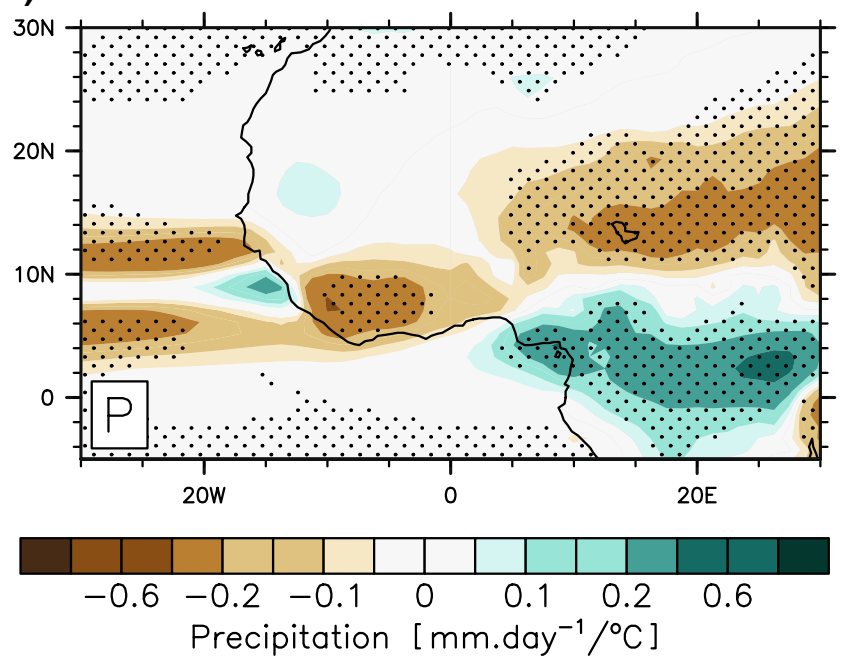

(d)

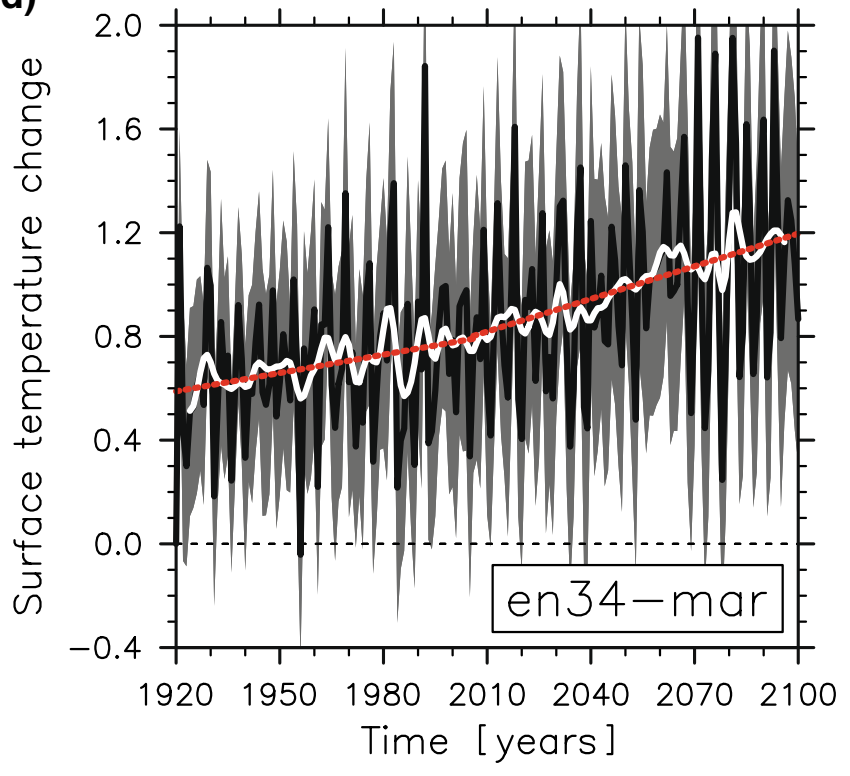

regression that is significantly different to zero, according to a Spearman's rank test, at the 95\% confidence level. d Evolution of the eastern Pacific-MAR temperature $\left({ }^{\circ} \mathrm{C}\right)$ in ASO [en34-mar; black line; see the black boxes on panel (a)], relative to the year 1920. The lowfrequency evolution of the en34-MAR gradient is obtained with a Lanczos filter (19 weights with a 9- year cut-off period; white line). Red lines indicate linear regressions over both 1920-2005 and 20062100 periods and the grey shading indicates the ensemble member spread, as defined by 2 times the standard error $\left(\frac{\text { ensemble-member }}{\sqrt{n}}\right.$, with $\left.n=40\right)$

The 1920-1980 change in precipitation is only associated with changes in the pattern of the atmospheric circulation (i.e. $\Delta P_{\text {shift }}$ ) (Fig. 6c) while the weakening of the tropical mean circulation becomes stronger as the global mean surface temperature increases. $\Delta P_{\text {therm }}$ is mostly associated 
Fig. 6 Ensemble mean change in a precipitation $(\Delta \mathrm{P}$; red $)$, $\Delta P_{d y n}$ (orange), $\Delta P_{\text {therm }}$ (green) and $\Delta P_{\text {cross }}$ (purple), in $\mathbf{c} \Delta P_{d y n}$ (orange), $\Delta P_{\text {weak }}$ (dark orange) and $\Delta P_{\text {shift }}$ (pink), e $\Delta P_{\text {therm }}$ (green), $\Delta P_{\text {qadv }}$ (blue) and $\Delta P_{\text {gres }}$ (brown), and in $\mathbf{g} \Delta \mathrm{P}$ (red), $\Delta P_{\text {qadvw }}$ (orange), $\Delta P_{\text {shiftres }}$ (light blue) and $\Delta P_{\text {cross }}$ (purple), for the Western Sahel in JJA.

$\mathbf{b}-\mathbf{d}, \mathbf{f}-\mathbf{h}$ same as in $\mathbf{a}-\mathbf{c}, \mathbf{e}-\mathbf{g}$ but for the central Sahel and in ASO. Anomalies are given relative to the year 1920. Units are in mm.day ${ }^{-1}$ (a)

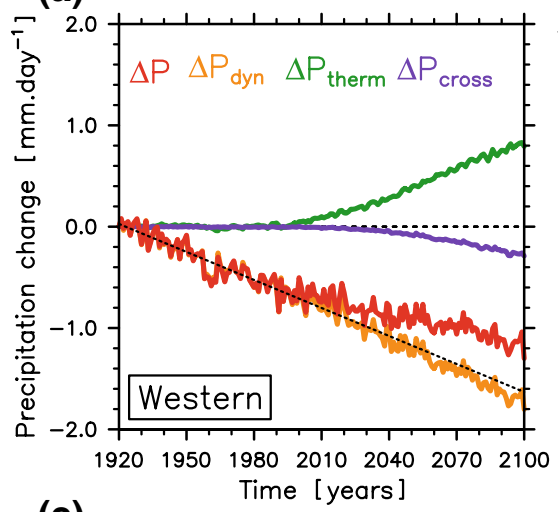

(c)

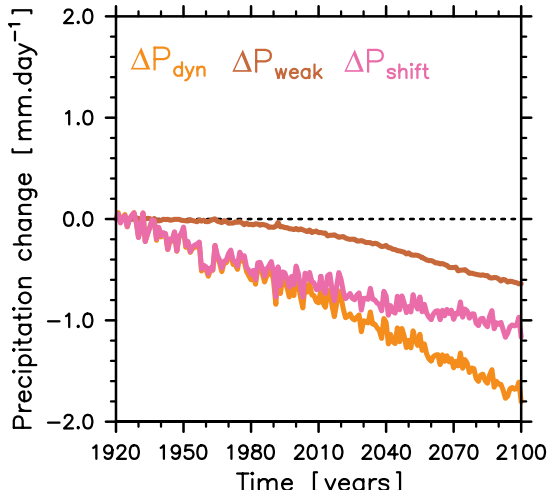

(e)

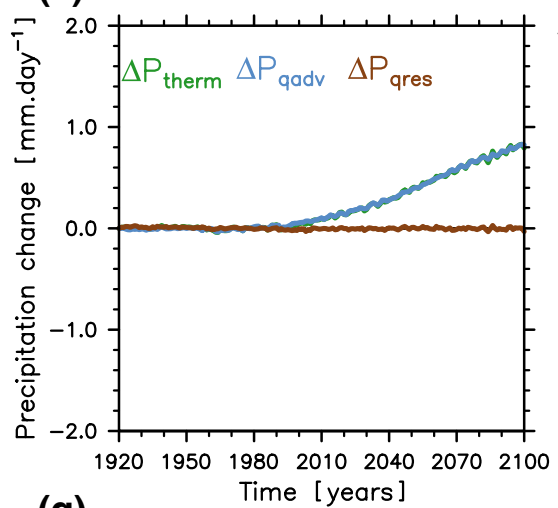

(g)

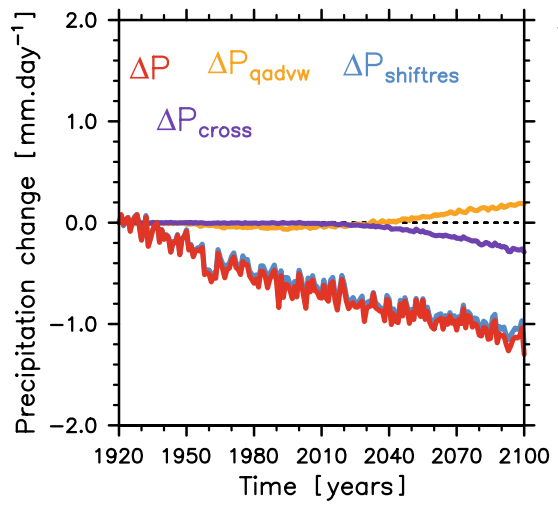

(b)

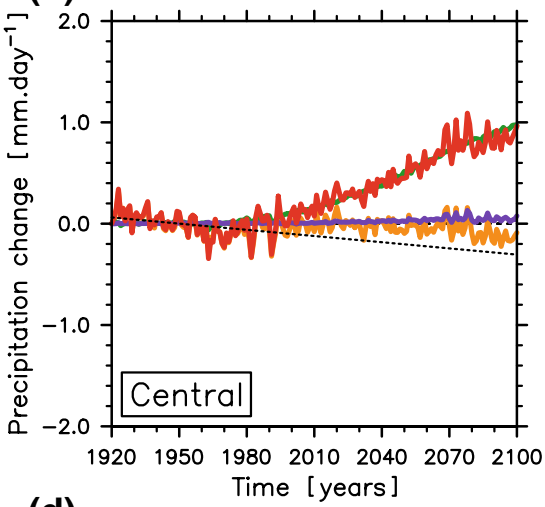

(d)

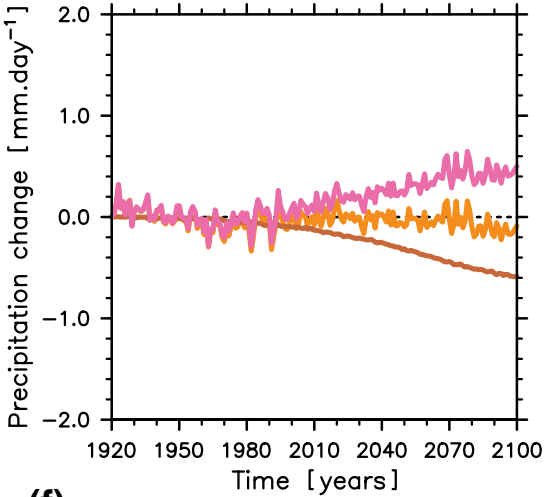

(f)

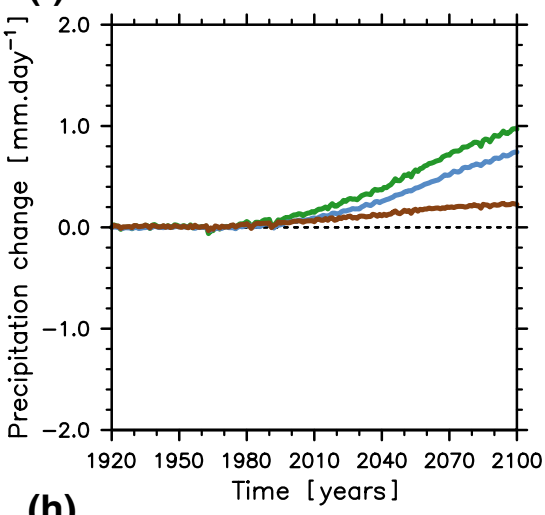

(h)

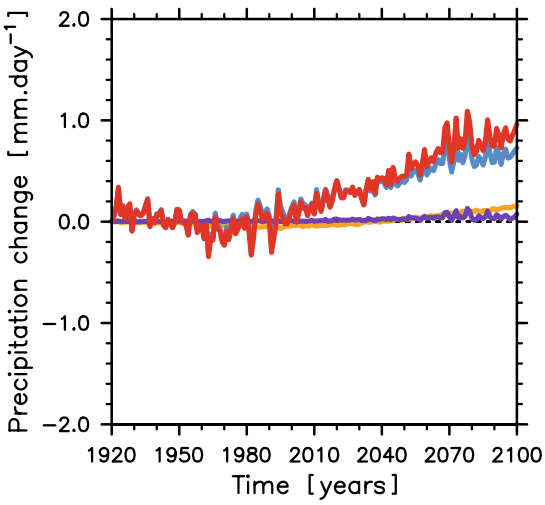


with a strengthening of the moisture advection from the ocean to land $\left(\Delta \mathrm{P}_{\text {qadv }}\right)$ (Fig. 6e).

The warming of the tropical SSTs is associated with both an enhanced moisture advection from the oceans $\left(\Delta \mathrm{P}_{\text {qadv }}\right)$, which increases precipitation over Sahel (Fig. 6e), over the ascent regions, and with a weakening of the tropical circulation $\left(\Delta \mathrm{P}_{\text {weak }}\right)$ that reduces precipitation (Ma et al. 2018) (Fig. 6c). Thus, both $\Delta \mathrm{P}_{\text {qadv }}$ and $\Delta \mathrm{P}_{\text {weak }}$ are strongly negatively correlated and there is a physical cancelation between $\Delta \mathrm{P}_{q a d v}$ and $\Delta \mathrm{P}_{\text {weak }}$ (Kent et al. 2015; Rowell and Chadwick 2018). Therefore, we combined both terms, with $\Delta \mathrm{P}_{\text {qadvw }}=\Delta \mathrm{P}_{\text {weak }}+\Delta \mathrm{P}_{\text {qadv }} . \Delta \mathrm{P}_{\text {res }}$ is a residual that is associated with changes in circulation, evaporation and vertical mixing (Chadwick et al. 2016). We combined $\Delta \mathrm{P}_{\text {res }}$ and $\Delta \mathrm{P}_{\text {shift }}$ that are associated with changes in the dynamic: $\Delta \mathrm{P}_{\text {shiftres }}=\Delta \mathrm{P}_{\text {shift }}+\Delta \mathrm{P}_{\text {res }} . \Delta \mathrm{P}_{\text {weak }}$ and $\Delta \mathrm{P}_{\text {qad }}$ partially cancel out and $\Delta \mathrm{P}_{q a d v w}$ is moderate and only increases after 2010 (Fig. 6g). Finally, the change in western Sahel precipitation is mostly associated with a shift in the circulation.

\subsubsection{Central Sahel precipitation change}

Central Sahel precipitation tends to decrease over the period 1920-1960, to increase over the period 1980-2080 and to be stabilized at the end of the twenty-first century (Fig. 4b).

Over the central Sahel, the change in precipitation is apparently explained by $\Delta P_{\text {therm }}$, because $\Delta P_{d y n}$ and $\Delta P_{\text {cross }}$ are moderate (Fig. 6b). However, the change in the atmospheric dynamic is moderate because its two components, $\Delta \mathrm{P}_{\text {shift }}$ and $\Delta \mathrm{P}_{\text {weak }}$ partially cancel each other (Fig. 6d). Moreover, the pattern of $\Delta P_{d y n}$ denotes a northward shift of the West African Monsoon east of $0^{\circ} \mathrm{W}$ (Fig. S7), with positive (negative) anomalies north (south) of $15^{\circ} \mathrm{N}$, leading to a rather low change when averaged between $10^{\circ} \mathrm{N}$ and $20^{\circ} \mathrm{N}$. $\Delta \mathrm{P}_{\text {weak }}$ decreases after the 1980 s while $\Delta \mathrm{P}_{\text {qadv }}$ increases after the 1980s, and $\Delta \mathrm{P}_{q a d v w}$ is then small over the central Sahel (Fig. 6h) suggesting that the change in central Sahel precipitation is mostly due to shifts in the circulation (Fig. 6h).

$\Delta \mathrm{P}_{\text {qadv }}$ and $\Delta \mathrm{P}_{\text {weak }}$ are relatively homogeneous over West Africa, but with strong values over the Guinean coast and the Cameroon highs (Fig. S7), where climatological precipitation is the highest. $\Delta \mathrm{P}_{\text {qadvw }}$ is then homogeneous over the Sahel. $\Delta \mathrm{P}_{q a d v w}$ is slightly positive because $\Delta \mathrm{P}_{\text {qadv }}$ is stronger than $\Delta \mathrm{P}_{\text {weak }}($ Fig. $7 \mathrm{a}, \mathrm{d})$. Both $\Delta \mathrm{P}_{\text {shift }}$ and $\Delta \mathrm{P}_{\text {res }}$ have a similar pattern (not shown), and $\Delta \mathrm{P}_{\text {shiftres }}$ is associated with a zonal dipole in precipitation change over the Sahel (Fig. 7b, e). As in Chadwick et al. (2016), the shift in the tropical circulation mostly explains thus the pattern in precipitation change. The shift in the circulation is stronger in JJA than in ASO over the western Sahel, explaining why the western Sahel precipitation decrease is stronger in the early rainy season.
Changes in the cross term $\left(\Delta \mathrm{P}_{\text {cross }}\right)$ are not negligible and also show a dipole (i.e., a decrease over the western Sahel and an increase over the central Sahel) (Fig. 7c, f). However, the pattern of $\Delta \mathrm{P}_{\text {cross }}$ exhibits some dissimilitude with the pattern of $\Delta \mathrm{P}$ and its intensity is lower than the dynamic term, over the Sahel.

\subsubsection{Role of regional changes}

Shifts in the circulation are strong over the Sahel. Changes in the circulation can be associated with both changes in sea surface temperature, both locally and globally, and with the warming of the Saharan desert that is associated with a strengthening of the monsoon circulation (Chadwick et al. 2019). To assess the respective roles of the SST warming and of the warming over land we use the AMIP simulations (Taylor et al. 2012), which are described in Sect. 2.

\subsubsection{Impacts of sea surface temperature change and $\mathrm{CO}_{2}$ concentration increase}

The net impact of a homogeneous warming of the SSTs is a southward shift of the West African monsoon and a decrease in Sahel precipitation (Fig. 8a). Gaetani et al. (2017) found that a warming of the SSTs leads to a decrease in Sahel precipitation through large-scale changes of the atmospheric circulation, resulting in increased subsidence over the Sahel. They showed that the large-scale circulation is partly driven by the warming of the tropical and equatorial Atlantic Ocean, where ascents are associated with largescale changes over the Indian Ocean, in a Walker-type circulation. In addition, Hill et al. $(2017,2018)$ have shown that the decrease in Sahel precipitation is associated with an increase in meridional moist static energy gradient spanning the Sahel and northerly dry air advection from the Sahara desert to the Sahel.

The amipFuture simulation shows that a heterogeneous increase of the SSTs (Fig. S8) is also associated with a decrease in precipitation over the Sahel (Fig. 8b). Though the difference between the amip $4 \mathrm{k}$ and amipFuture is not negligible, two-thirds of the precipitation anomalies are due only to the homogeneous warming of the global ocean, shedding light on the prominent importance of the tropical mean warming of the SSTs in comparison to a change in SST gradients. For both homogeneous and heterogeneous SST warming, changes in precipitation are mostly due to changes in the location of the atmospheric circulation, with the warming of the SST leading to a southward shift of the monsoon (Fig. 9a and Fig. 9b; and Fig S8). Besides, a warming of the SST is associated with a strengthening of the maritime moisture advection, which is partly offset by the weakening of the tropical mean circulation (i.e., $\Delta \mathrm{P}_{q a d v w}$ is close to zero) (Fig. S10). The impacts of both homogeneous 
(a)
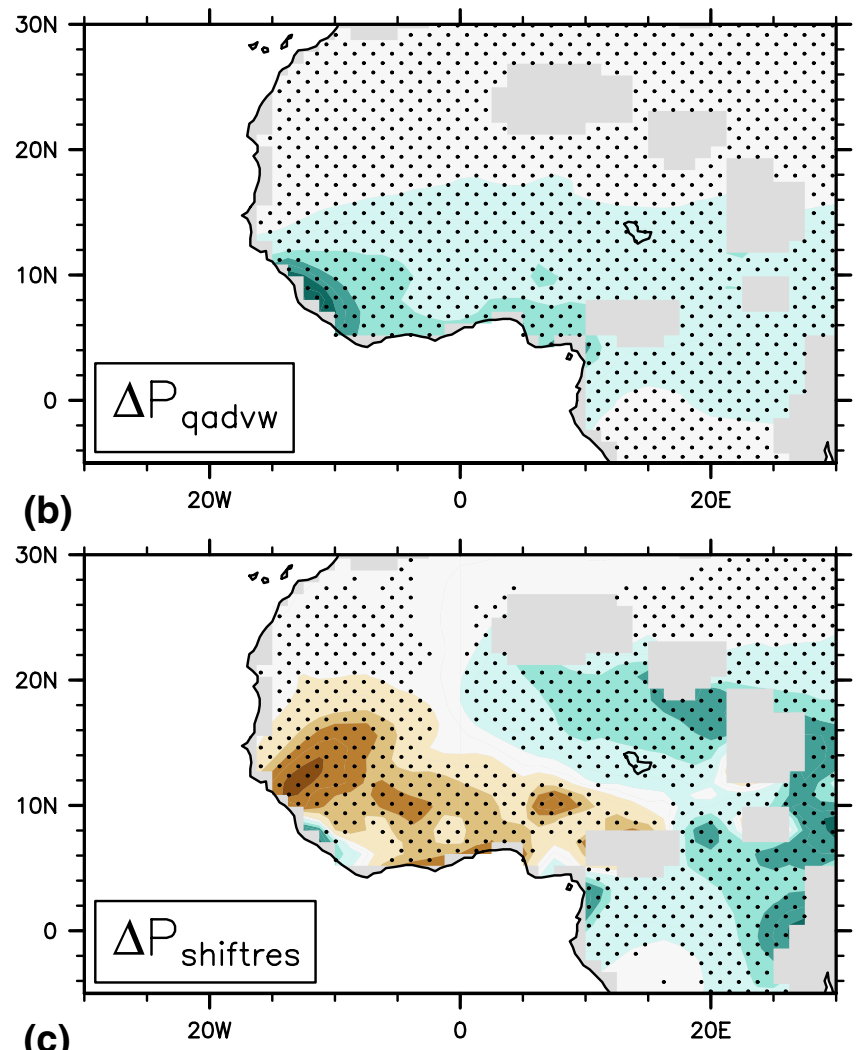

(c)
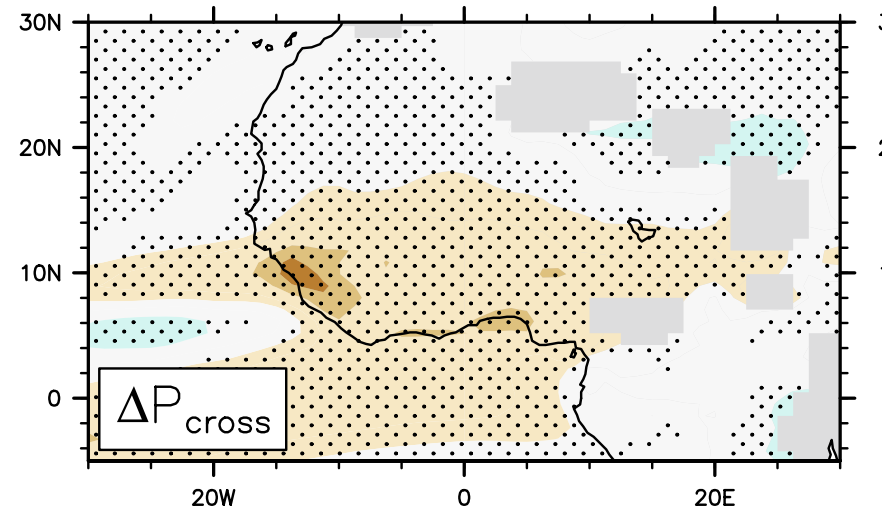

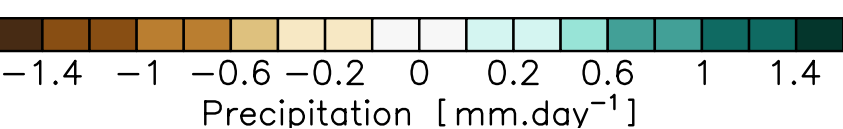

(d)
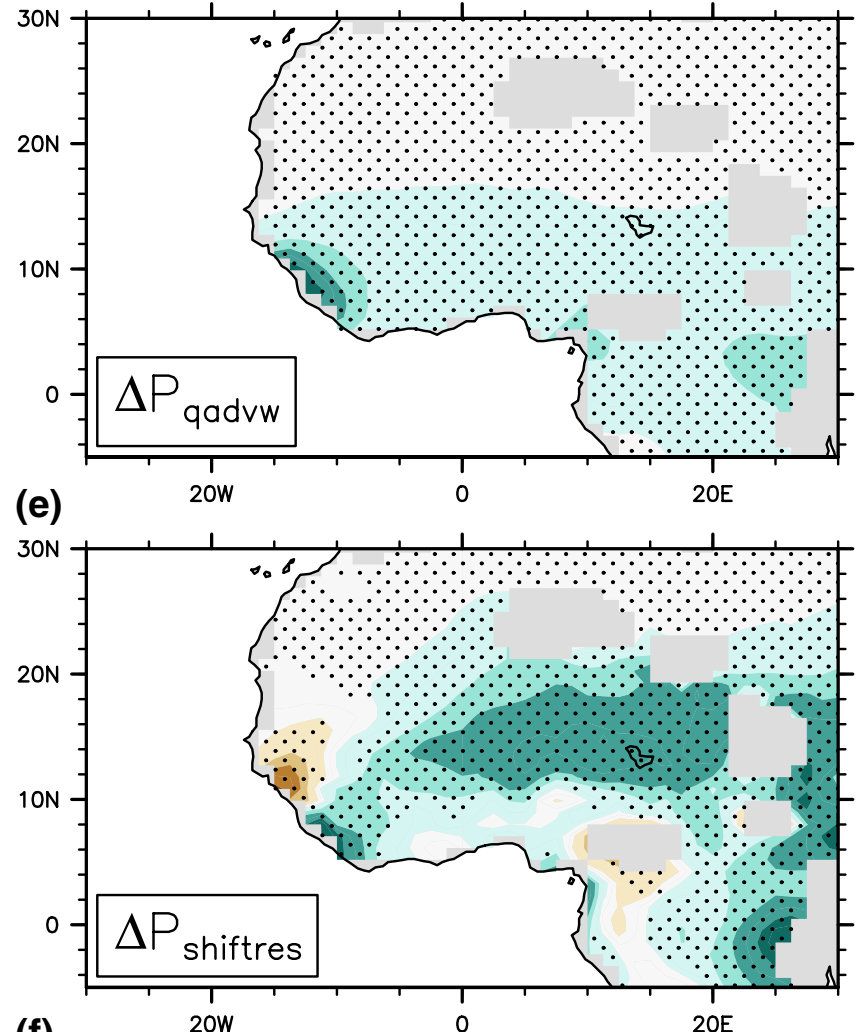

(f)

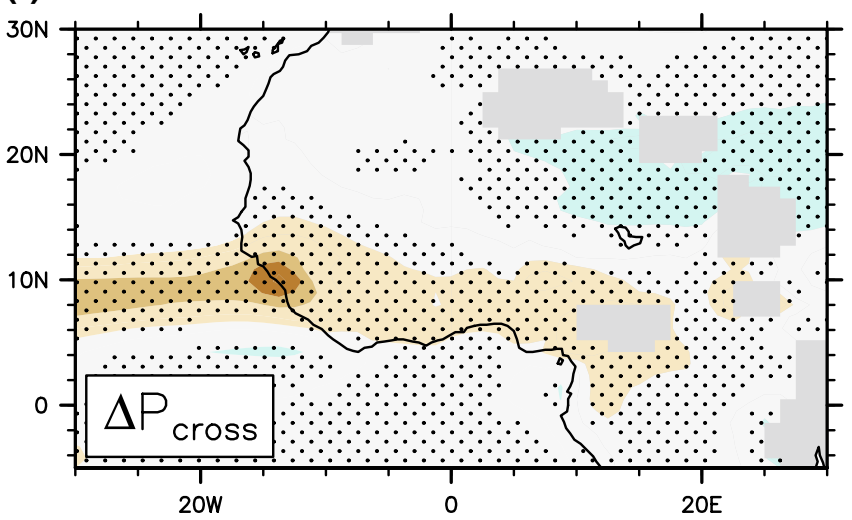

Fig. 7 a Ensemble mean change in a $\Delta P_{\text {qadvw }}$, b $\Delta P_{\text {shiftres }}$ and c $\Delta P_{\text {cross }}$ (in mm.day ${ }^{-1}$ ) in JJA. d-f same as in a-c but in ASO. Changes are obtained by the difference between the period 20602099 (RCP8.5 emission scenario) and the historical period 1960-

and heterogeneous warming of the SSTs on $\Delta \mathrm{P}$ pattern are explained by $\Delta \mathrm{P}_{\text {shift }}$ (Fig. 9a, b) and $\Delta \mathrm{P}_{\text {shiftres }}$ (Fig. S9). Interestingly, a homogeneous warming of the SST does not only lead to a decrease in Sahel precipitation, but also to a southward shift of the monsoon.
1999 (historical emission scenario). Stippling represents the gridpoints where at least $80 \%$ of the simulations agree with the sign of the multi-model mean precipitation change

The amip4xCO2 simulations show a relatively large warming over land in JAS over the northern Hemisphere, including the Saharan desert, north of the Sahel (Fig. S8). The maritime advection (i.e. $\Delta \mathrm{P}_{q a d v}$ ) and the change in the tropical mean circulation (i.e., $\Delta \mathrm{P}_{\text {weak }}$ ) are low (not shown) because SSTs are prescribed and do not increase in the 
(a) amip4k-amip

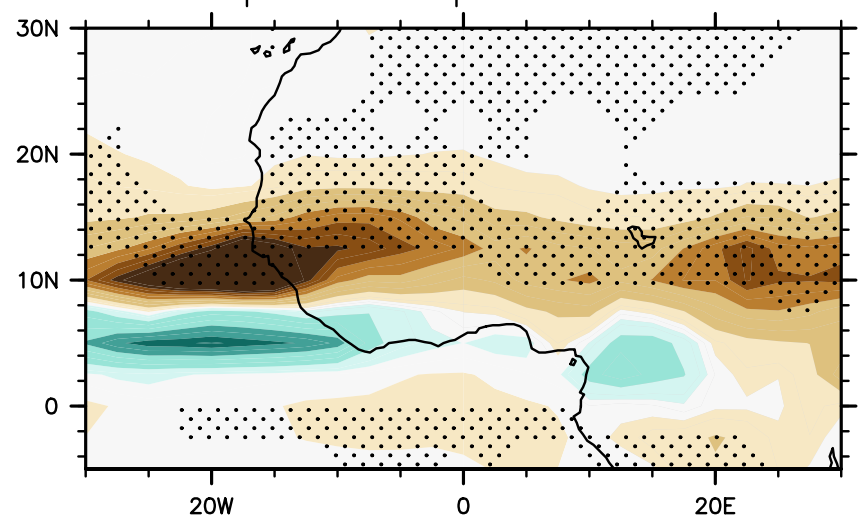

(c) amip $4 \times \mathrm{CO} 2-$ amip

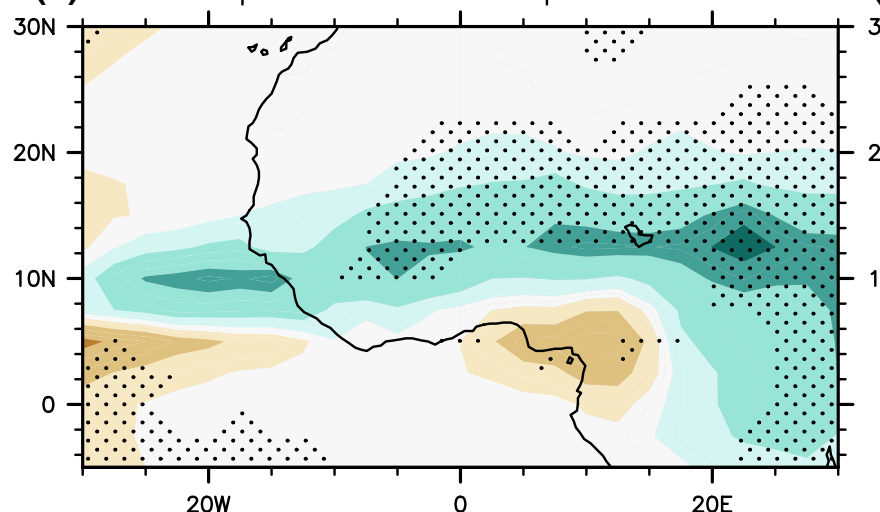

(b) amipFuture-amip

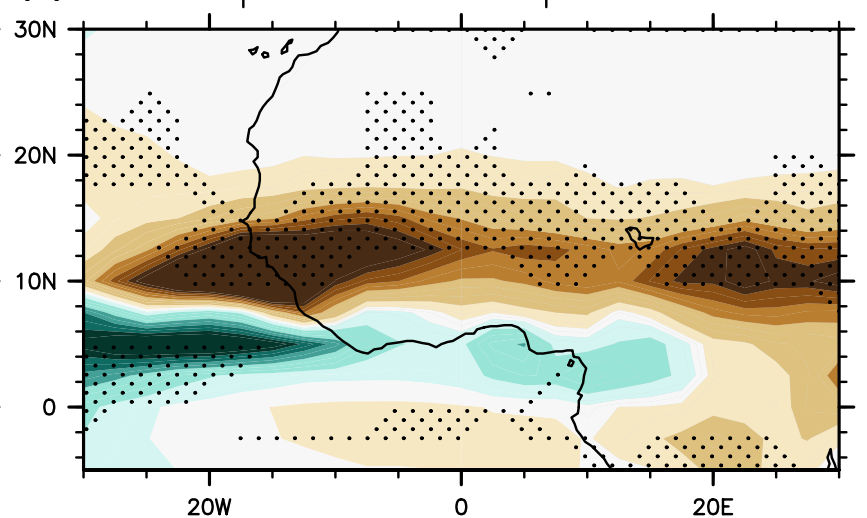

(d)

$(a)+(c)$

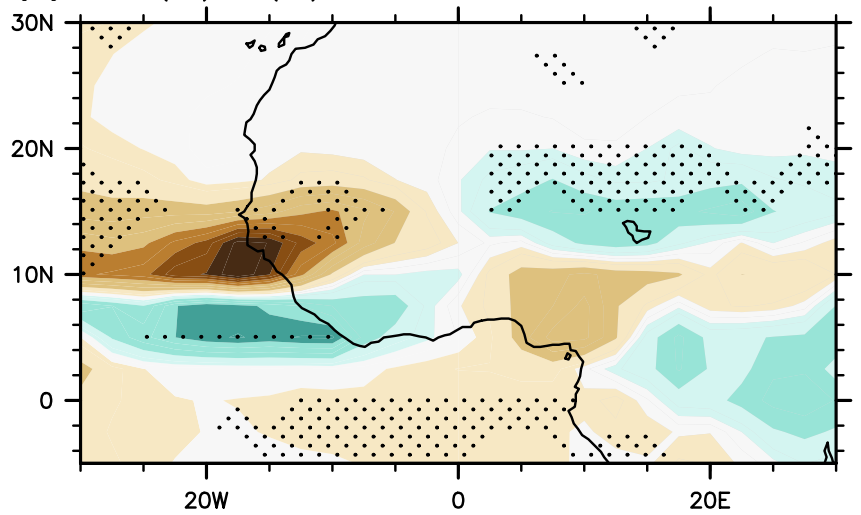

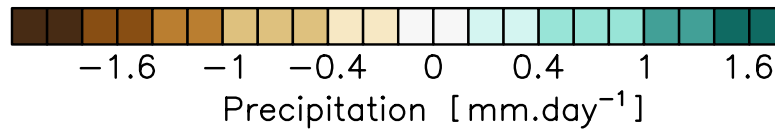

Fig. 8 Difference in July-September ensemble mean precipita-

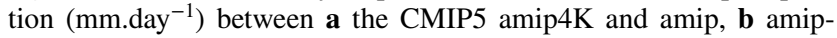
Future and amip, $\mathbf{c}$ amip4xCO2 and amip simulations. d Sum of the

amip4xCO2 simulations, relative to the amip simulation (Fig. S8). The monsoon circulation shifts northward and Sahel precipitation increases (Figs. 8c and 9c). This is consistent with the results of Gaetani et al. (2017), who have shown that the moist static energy content increases in the lower troposphere, in response to an increase in land temperature, driving the monsoon system to shift northward.

Changes in SSTs are associated with a strong decrease in precipitation over the western Sahel, and with a southward shift of the ITCZ over the Atlantic Ocean (Fig. 8a, b). The increase in greenhouse gases concentration is associated with an increase in precipitation over the central Sahel, while changes over the western Sahel are not robust (Fig. 8c). A zonal dipole in precipitation over the Sahel does not clearly appear due to the warming of the SST nor to the warming of northern Africa. The addition of the impacts of a warming of the SSTs (amip4K), that is the
amip4K-amip and amip4xCO2-amip differences. Stippling represents the grid-points where at least $80 \%$ of the models agree with the sign of the multi-model mean precipitation change

slow response to climate change, and of the increase in greenhouse gases (amip4xCO2), that is the fast response to climate change, shows a zonal dipole with a northward shift of the monsoon over the central Sahel and a southward shift of the monsoon over the western Sahel (Figs. 8d and 9d). This suggests that the zonal dipole is neither due to changes in SSTs nor to the warming of northern Africa, but to a combination of both.

\subsubsection{Role of the strength and location of the Saharan Heat low}

No clear changes of the SHL index [Eq. 11] are obtained during the early twentieth century, and the decrease in western Sahel precipitation is thus not associated with changes of the Heat Low strength and location between the year 1920 and the year 1980 (Fig. 10a, c). After 1980, the decrease in geopotential height field at $925 \mathrm{hPa}$ (ZG925) is robust as 

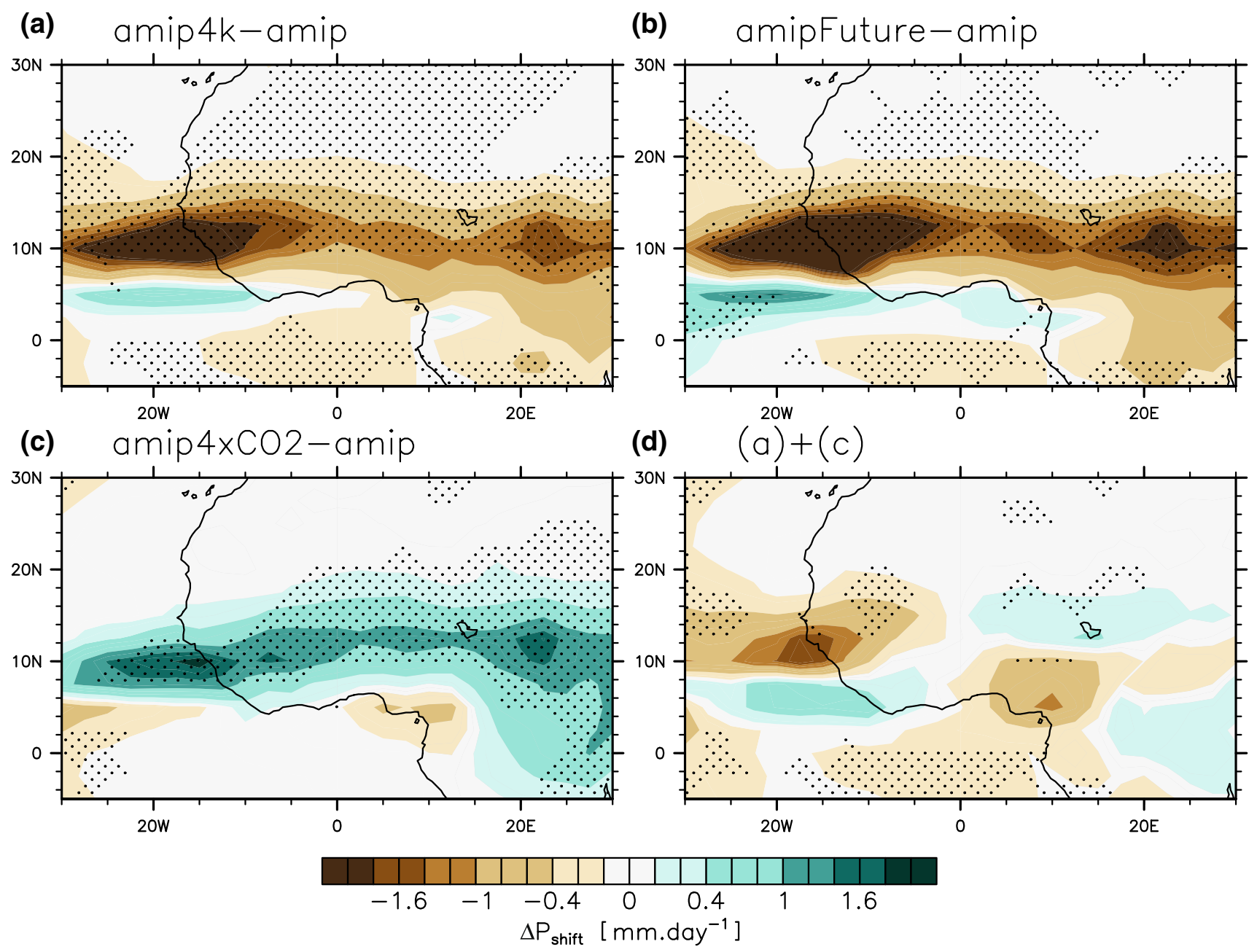

Fig. 9 As in Fig. 8 but for $\Delta P_{\text {shift }}$

reproduced by all members. The post-1980s deepening of the Heat Low (Fig. 10a) is associated with an increase in surface air-temperature and a decrease in sea level pressure over northern Africa (Fig. S6). The regression pattern of the IV component of SHL index onto IV component of precipitation shows a relationship between the strength of the SHL and central Sahel precipitation (Fig. 10b). A strengthening of the SHL (i.e.,negative anomalies in ZG925) is associated with an increase in precipitation over the central Sahel and over West Africa, South of $10^{\circ} \mathrm{N}$ (Fig. 10b). To confirm this result, we also use a second metric, accounting for the $3 \mathrm{D}$ structure of the shallow circulation, with the LLAT index (i.e., ZG700-ZG925). LLAT increases with time, also showing a strengthening of the SHL in a warmer climate (Fig. S11). However, the regression between the LLAT index and Sahel precipitation does not show significant impacts due to a strengthened heat low over Sahel (Fig. S11). This is consistent with Shekhar and Boos (2017), which have shown that impact a change in the strength of the SHL is unclear on Sahel precipitation.

Shekhar and Boos (2017) have shown that the impact of a shift in the SHL location is associated with robust changes over the Sahel in reanalysis. In a warmer climate, SHL is projected to move northward (Dunning et al. 2018) (Fig. 10c). A northward shift of the SHL is also shown with the LLAT index (Fig. S11). A northward shift of the Saharan low is associated with an increase in precipitation over the central Sahel in CESM1 (Fig. 10d and Fig. S11). The projected northward shift of the SHL could therefore lead to an increase in precipitation over the Sahel in a warmer climate. However, the impact of a northward shifted heat low is not significant over the western Sahel (Fig. 10d). Therefore, we suggest that changes in the location of the SHL contributes to the zonal contrast because impacting more strongly the central than the western Sahel, causing heterogeneous changes in precipitation (Fig. 10d). This is also 
(a)

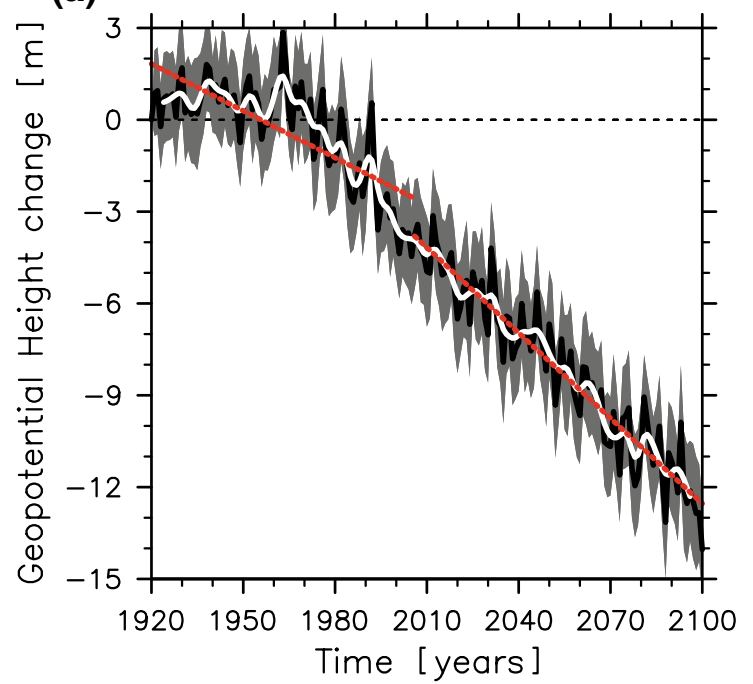

(c)

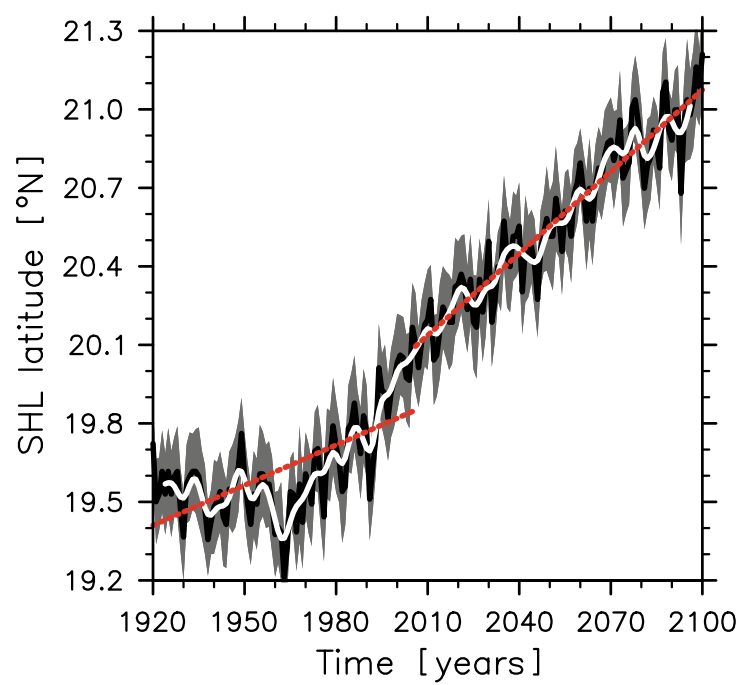

Fig. 10 a Ensemble mean evolution of the SHL index (m) in JAS (black line), relative to the year 1920. The low-frequency evolution of the SHL index is obtained with a Lanczos filter (19 weights with a 9year cut-off period; white line). Red lines indicate linear regressions over both 1920-2005 and 2006-2100 periods and the grey shading indicates the ensemble member spread, as defined by 2 times the standard error $\left(\frac{\text { ensemble-member }}{\sqrt{n}}\right.$, with $\left.n=40\right)$. b Ensemble mean of precipi-

consistent with the results of the $4 \mathrm{xCO} 2$ simulations, in which an increase in northern African surface temperature is associated with a strengthening of the SHL (as shown in Gaetani et al. 2017), and with an increase in precipitation over the central Sahel only (Fig. 8c). However, impacts on the SHL cannot explain, by themselves, the establishment and future evolution of the zonal contrast in precipitation over the Sahel. (b)

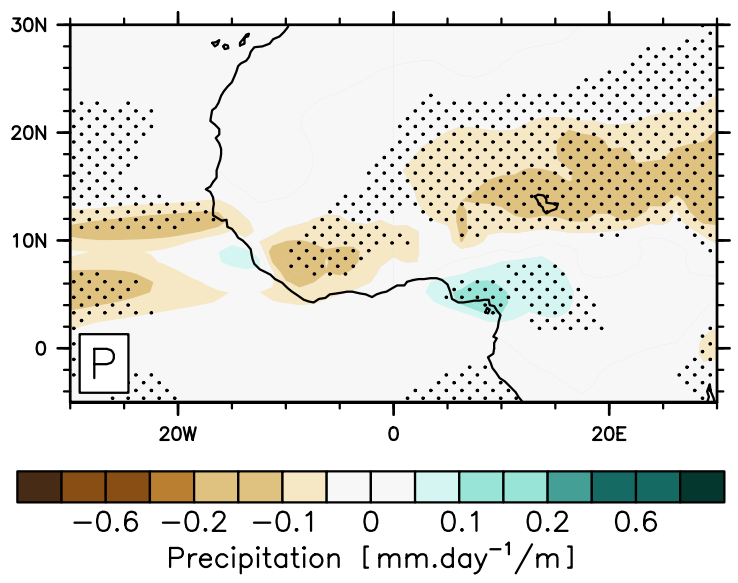

(d)

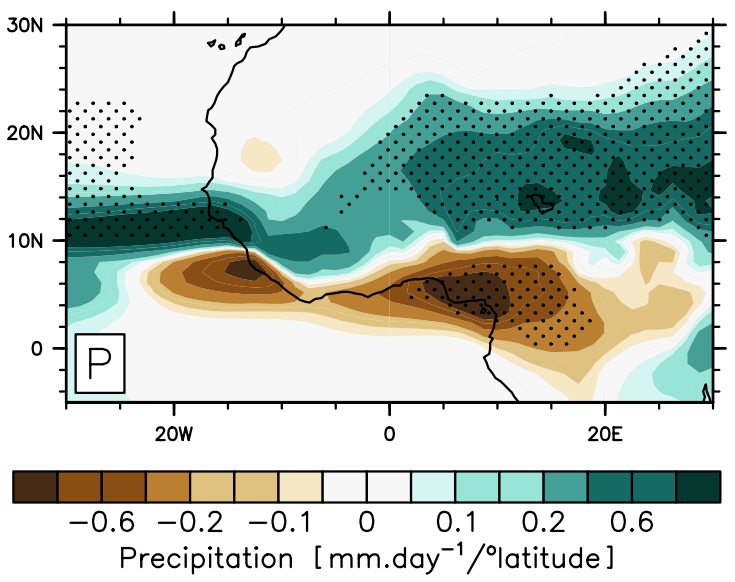

tation regressed onto the SHL index $\left(\mathrm{mm} \cdot \mathrm{day}^{-1} / \mathrm{m}\right)$ in JAS over the period 1920-2100 for the internal variability component of both precipitation and SHL index, as first computed for each member. $\mathbf{c}$ as in a but for the location, in latitude, of the SHL. $\mathbf{d}$ as in $\mathbf{b}$ but with precipitation regressed onto the latitudinal location of the SHL (mm. day $^{-1} /{ }^{\circ}$ latitude). Stippling indicates that at least $80 \%$ of the members are simulating a regression that is significantly different to zero, according to a Spearman's rank test at the $95 \%$ confidence level

\section{Discussion}

The results obtained with the CMIP5 amip simulations might not be representative of the response of CESM1. For instance, the SST pattern used to force the amipFuture simulations is characterised by a future strengthening of the TSA/TNA temperature gradient (Fig. S9) that is not found in CESM1. Within the amip ensemble, we analysed the outputs of the CCSM4 model, a model developed at NCAR, and that produces the same pattern in precipitation 
change as in CESM1, under the RCP8.5 emission scenario. The warming of the SSTs (amip4K and amipFuture) also produces in CCSM4 a southward shift of the monsoon circulation and a decrease in Sahel precipitation (Fig. S12). These results bring confidence on the fact that the results obtained within the CMIP5 ensemble could be similar to CESM1, that a warming of the SST (increase in GHG concentration) is associated with a decrease (an increase) in Sahel precipitation in CESM1. Meanwhile, we might have underestimated the importance of SST gradients on Sahel precipitation with the AMIP simulations. The forcing that is imposed in amipFuture is defined from an ensemble mean of the CMIP3 simulations, and anomalies are expected to be of weaker magnitude than in each model.

By analysing the anomalies in western Sahel precipitation, for each month of the year, we also show that the decrease in precipitation, due to the warming of the SST is the strongest in July-August, during the first half of the rainy season, while the land warming is associated with an increase in precipitation, later in the year, from August to October (Fig. S13). The sign (negative) and timing (during the first half of the rain seasons) of western Sahel precipitation change, could thus be due to the warming of the SSTs.

We assess whether the zonal contrast in precipitation over the Sahel in model simulations is also a mode of variability in observations. We performed an Empirical Orthogonal Function (EOF) on observed JAS Sahel precipitation $\left(20^{\circ} \mathrm{W}-20^{\circ} \mathrm{E} ; 10^{\circ}-20^{\circ} \mathrm{N}\right)$, using several datasets, i.e., CRU, GPCC, PRECL, UDEL and 20CR. Results indicate that the zonal contrast is a mode of variability in observations, but only explains between 6 and $9 \%$ of the total precipitation variability (Fig. S14). The same analysis is repeated using the twentieth century reanalysis, for which the zonal contrast has a stronger importance, explaining $20 \%$ of the total precipitation variability. This may suggest that the zonal contrast could then be overestimated in climate models. The regression of the observed ARPI index onto the surface air temperature shows contrasted results between CESM1 and observations (Fig. 2, Fig. S15). Differences between CESM1 and observations at simulating the relationship between SST and ARPI could be due to the inability of CESM1 to simulate the Sahel precipitation variability (Monerie et al. 2017). Therefore we cannot exclude that simulated changes in Sahel zonal contrast could be due to biases in climate models, as suggested by James et al. (2015) for western Sahel precipitation.

The ARPI could be used as a metric to evaluate and select models that are able or unable to simulate Sahel precipitation variability, as done in Cook and Vizy (2006) with the Sahel/Guinean coast Sahel precipitation dipole. However, we show here that the zonal dipole is associated with different mechanisms when accounting or not for the forced response. Unlike in a warmer climate, the simulated zonal contrast, over the historical period, is mainly associated with the thermal gradients over different oceanic basins (i.e., variations in the tropical Atlantic and Pacific Ocean). This could limit the possibility to select a set of the best models based on their ability to simulate the historical observed climate variability since climate variability could be associated with mechanisms of different magnitudes in both historical and warmer climate.

\section{Conclusion}

We used the Community Earth System Model CESM1 (Kay et al. 2015) Large Ensemble to investigate the zonal dipole in Sahel precipitation. The large ensemble consists of a set of 40 simulations and allows analysing the simulated climate over the twentieth century (under the historical scenario) and the twenty-first century (under the RCP8.5 emission scenario). Moreover, with 40 members we can robustly estimate the forced response and internal climate variability. We confirm that a zonal contrast (i.e., western/central) in Sahel precipitation is a robust feature of the CESM1 projections.

We clarified here that:

Over the central Sahel, precipitation increases due to a northward shift of the monsoon circulation $\left(\Delta P_{\text {shiftres }}\right)$. The moistening of the low-level atmosphere through moisture advection (the thermodynamic $\Delta P_{q a d v w}$ component) compensate the decrease in precipitation that is associated with the weakening of the tropical mean circulation $\left(\Delta P_{\text {weak }}\right)$, leading to a moderate increase in precipitation ( $\Delta P_{q a d v w}$ is positive) (Fig. 6).

Western Sahel precipitation decreases strongly between June and August over both the 20th and the twentyfirst century. These changes are mostly contributed by a change in the atmospheric dynamics, while thermodynamic changes damp the decrease in precipitation (Fig. 6). During the historical period the decrease in western Sahel precipitation is associated with the tropical South Atlantic/tropical North Atlantic thermal gradient, which pulls the monsoon cell southward. However, the cross-equatorial Atlantic gradient does not strengthen with time, and is therefore not able to explain the magnitude of the decrease in western Sahel precipitation over the twenty-first century in CESM1.

We propose that the global warming induces a zonal contrast in precipitation due to the competitive effects of the warming over land, that is due to an increase in greenhouse gases concentration, and that is leading to an increase in precipitation over the central Sahel, and to the warming of the SST, which is associated with a southward shift of the monsoon circulation, that is par- 
ticularly strong over the western Sahel. This is consistent with Gaetani et al. (2017), which have shown that the Sahel precipitation zonal contrast is contributed by both increases in SST and $\mathrm{CO}_{2}$ concentration.

We show that changes in SST contrasts (i.e., the TNA/ TSA thermal gradient and ENSO) do not play a prominent role on the zonal precipitation contrast over the twenty-first century.

The Saharan Heat Low is often pointed out to explaining the East/West difference in Sahel precipitation change (Biasutti et al. 2009; Roehrig et al. 2011; Lavaysse et al. 2016). However, we only find a relationship between the location of the Heat Low and central Sahel precipitation.

In summary, we found that the Sahel precipitation zonal contrast in CESM1 is associated with two mechanisms: (1) the warming of northern Hemisphere is associated with a northward shift of the monsoon and an increase in central Sahel precipitation; (2) the warming of the SSTs is associated with a southward shift of the circulation.

We speculate that results could be strengthened by local feedbacks, through a modification of the location and strength of the Sahara Heat Low and, of the content in soil moisture through land-atmosphere feedbacks (Koster et al. 2004; Wang and Alo 2012; Mariotti et al. 2014).

A caveat of this study relies on the limited ability of CESM1 to simulate the observed Sahel precipitation variability (Monerie et al. 2017) and the observed SST_-ARPI relationship (Fig. S13). Further work is then needed to better document changes in observed ARPI. A multi-model analysis should also be performed to assess the relationship between Atlantic tropical SSTs with the West African monsoon, as done with the Atlantic Multidecadal Variability (Martin and Thorncroft 2014a), the Tropical Easterly Jet (Whittleston et al. 2017) and the Heat Low (Dixon et al. 2016). Another caveat of the study is that we used monthly means while start and demise dates of the monsoon are projected to be delayed by a few days over Sahel (Dunning et al. 2018). Results might be slightly different using simulated rainy season period, especially when accounting for seasonal changes.

Acknowledgements E. M. were supported by the Spanish Project CGL2017-86415-R and B. D. by the Natural Environment Research Council (NERC) via the National Centre for Atmospheric Science (NCAS). We acknowledge the World Climate Research Programme's Working Group on Coupled Modelling, which is responsible for CMIP, and we thank the climate modelling groups for producing and making available their model output. For CMIP, the US Department of Energy's Program for Climate Model Diagnosis and Intercomparison provides coordinating support and led development of software infrastructure in partnership with the Global Organization for Earth System Science Portals. We acknowledge the CESM Large Ensemble Community Project and supercomputing resources provided by
NSF/CISL/Yellowstone for providing the climate model outputs. The authors thank the two anonymous reviewers for their constructive comments and suggestions.

Open Access This article is licensed under a Creative Commons Attribution 4.0 International License, which permits use, sharing, adaptation, distribution and reproduction in any medium or format, as long as you give appropriate credit to the original author(s) and the source, provide a link to the Creative Commons licence, and indicate if changes were made. The images or other third party material in this article are included in the article's Creative Commons licence, unless indicated otherwise in a credit line to the material. If material is not included in the article's Creative Commons licence and your intended use is not permitted by statutory regulation or exceeds the permitted use, you will need to obtain permission directly from the copyright holder. To view a copy of this licence, visit http://creativecommons.org/licenses/by/4.0/.

\section{References}

Akinsanola AA, Zhou W (2018) Ensemble-based CMIP5 simulations of West African summer monsoon rainfall: current climate and future changes. Theor Appl Climatol. https://doi.org/10.1007/ s00704-018-2516-3

Akinsanola AA, Zhou W (2019) Projections of West African summer monsoon rainfall extremes from two CORDEX models. Clim Dyn 52:2017-2028. https://doi.org/10.1007/s00382-018-4238-8

Almazroui M, Saeed F, Saeed S et al (2020) Projected change in temperature and precipitation over Africa from CMIP6. Earth Syst Environ. https://doi.org/10.1007/s41748-020-00161-x

Barros VR, Field CB, Dokke DJ et al (2014) Climate change 2014: impacts, adaptation, and vulnerability-part B: regional aspectscontribution of working group ii to the fifth assessment report of the intergovernmental panel on climate change

Biasutti M (2013) Forced Sahel rainfall trends in the CMIP5 archive. J Geophys Res Atmos 118:1613-1623. https://doi.org/10.1002/ jgrd.50206

Biasutti M, Sobel AH, Camargo SJ (2009) The role of the Sahara low in summertime sahel rainfall variability and change in the CMIP3 models. J Clim 22:5755-5771. https://doi.org/10.1175/2009J CLI2969.1

Bony S, Webb M, Bretherton C et al (2011) CFMIP: towards a better evaluation and understanding of clouds and cloud feedbacks in CMIP5 models. Clivar Exchanges 56(2):20-22

Bordoni S, Schneider T (2008) Monsoons as eddy-mediated regime transitions of the tropical overturning circulation. Nat Geosci 1:515-519. https://doi.org/10.1038/ngeo248

Caminade C, Terray L (2010) Twentieth century Sahel rainfall variability as simulated by the ARPEGE AGCM, and future changes. Clim Dyn 35:75-94. https://doi.org/10.1007/s00382-009-0545-4

Chadwick R, Boutle I, Martin G (2013) Spatial patterns of precipitation change in CMIP5: why the rich do not get richer in the tropics. J Clim 26:3803-3822. https://doi.org/10.1175/JCLI-D-12-00543.1

Chadwick R, Good P, Willett K (2016) A Simple Moisture Advection Model of Specific Humidity Change over Land in Response to SST Warming. J Clim 29:7613-7632. https://doi.org/10.1175/ JCLI-D-16-0241.1

Chadwick R, Ackerley D, Ogura T, Dommenget D (2019) Separating the influences of land warming, the direct $\mathrm{CO} 2$ effect, the plant physiological effect, and SST warming on regional precipitation changes. J Geophys Res Atmos 124:624-640. https://doi. org/10.1029/2018JD029423 
Chen M, Xie P, Janowiak JE, Arkin PA (2002) Global land precipitation: a 50-yr monthly analysis based on gauge observations. J Hydrometeorol 3:249-266. https://doi.org/10.1175/15257541(2002)003<0249:GLPAYM > 2.0.CO;2

Compo GP, Whitaker JS, Sardeshmukh PD (2006) Feasibility of a 100year reanalysis using only surface pressure data. Bull Am Meteorol Soc 87:175-190. https://doi.org/10.1175/BAMS-87-2-175

Cook KH, Vizy EK (2006) Coupled model simulations of the West African monsoon system: twentieth- and twenty-first-century simulations. J Clim 19:3681-3703. https://doi.org/10.1175/JCLI3 814.1

Cook BI, Smerdon JE, Seager R, Coats S (2014) Global warming and 21st century drying. Clim Dyn 43:2607-2627. https://doi. org/10.1007/s00382-014-2075-y

Deser C, Tomas RA, Sun L (2014) The role of ocean-atmosphere coupling in the zonal-mean atmospheric response to arctic sea ice loss. J Clim 28:2168-2186. https://doi.org/10.1175/JCLID-14-00325.1

Diallo I, Giorgi F, Deme A et al (2016) Projected changes of summer monsoon extremes and hydroclimatic regimes over West Africa for the twenty-first century. Clim Dyn 47:3931-3954. https://doi. org/10.1007/s00382-016-3052-4

Dixon RD, Daloz AS, Vimont DJ, Biasutti M (2016) Saharan heat low biases in CMIP5 models. J Clim 30:2867-2884. https://doi. org/10.1175/JCLI-D-16-0134.1

Druyan LM (2011) Studies of 21st-century precipitation trends over West Africa. Int J Climatol 31:1415-1424. https://doi. org/10.1002/joc. 2180

Dunning CM, Black E, Allan RP (2018) Later Wet Seasons with more intense rainfall over Africa under future climate change. J Clim 31:9719-9738. https://doi.org/10.1175/JCLI-D-18-0102.1

Folland CK, Palmer TN, Parker DE (1986) Sahel rainfall and worldwide sea temperatures, 1901-85. Nature 320:602

Fontaine B, Gaetani M, Ullmann A, Roucou P (2011a) Time evolution of observed July-September sea surface temperature-Sahel climate teleconnection with removed quasi-global effect (1900 2008). J Geophys Res Atmos. https://doi.org/10.1029/2010J D014843(116:n/a--n/a)

Fontaine B, Roucou P, Monerie P-A (2011b) Changes in the African monsoon region at medium-term time horizon using 12 AR4 coupled models under the A1b emissions scenario. Atmos Sci Lett. https://doi.org/10.1002/asl.321

Gaetani M, Flamant C, Bastin S et al (2017) West African monsoon dynamics and precipitation: the competition between global SST warming and $\mathrm{CO} 2$ increase in CMIP5 idealized simulations. Clim Dyn 48:1353-1373. https://doi.org/10.1007/s00382-016-3146-Z

Giannini A (2010) Mechanisms of climate change in the semiarid African Sahel: the local view. J Clim 23:743-756. https://doi. org/10.1175/2009JCLI3123.1

Haarsma RJ, Selten FM, Weber SL, Kliphuis M (2005) Sahel rainfall variability and response to greenhouse warming. Geophys Res Lett. https://doi.org/10.1029/2005GL023232

Harris I, Jones PD, Osborn TJ, Lister DH (2014) Updated high-resolution grids of monthly climatic observations: the CRU TS3.10 dataset. Int J Climatol 34:623-642. https://doi.org/10.1002/joc.3711

Hawkins E, Sutton R (2011) The potential to narrow uncertainty in projections of regional precipitation change. Clim Dyn 37:407-418. https://doi.org/10.1007/s00382-010-0810-6

Held IM, Soden BJ (2006) Robust responses of the hydrological cycle to global warming. J Clim 19:5686-5699. https://doi.org/10.1175/ JCLI3990.1

Held IM, Delworth TL, Lu J et al (2005) Simulation of Sahel drought in the 20th and 21st centuries. Proc Natl Acad Sci USA 102:1789117896. https://doi.org/10.1073/pnas.0509057102

Hill SA, Ming Y, Held IM, Zhao M (2017) A moist static energy budget-based analysis of the Sahel rainfall response to uniform oceanic warming. J Clim 30:5637-5660. https://doi.org/10.1175/ JCLI-D-16-0785.1

Hill SA, Ming Y, Zhao M (2018) Robust responses of the sahelian hydrological cycle to global warming. J Clim 31:9793-9814. https ://doi.org/10.1175/JCLI-D-18-0238.1

Hoerling M, Hurrell J, Eischeid J, Phillips A (2006) Detection and attribution of twentieth-century northern and southern African rainfall change. J Clim 19:3989-4008. https://doi.org/10.1175/ JCLI3842.1

Hunke EC, Lipscomb WH, Turner AK et al (2010) CICE: the los alamos sea ice model documentation and software user's manual version 4.1 LA-CC-06-012. In: T-3 fluid dynamics group, Los Alamos National Laboratory 675, p 500

Hurrell JW, Holland MM, Gent PR et al (2013) The community earth system model: a framework for collaborative research. Bull Am Meteorol Soc 94:1339-1360. https://doi.org/10.1175/BAMSD-12-00121.1

James R, Washington R, Jones R (2015) Process-based assessment of an ensemble of climate projections for West Africa. J Geophys Res Atmos 120:1221-1238. https://doi.org/10.1002/2014JD0225 13

Joly M, Voldoire A, Douville H et al (2007) African monsoon teleconnections with tropical SSTs: validation and evolution in a set of IPCC4 simulations. Clim Dyn 29:1-20. https://doi.org/10.1007/ s00382-006-0215-8

Kay JE, Deser C, Phillips A et al (2015) The community earth system model (CESM) large ensemble project: a community resource for studying climate change in the presence of internal climate variability. Bull Am Meteorol Soc 96:1333-1349. https://doi. org/10.1175/BAMS-D-13-00255.1

Kent C, Chadwick R, Rowell DP (2015) Understanding uncertainties in future projections of seasonal tropical precipitation. J Clim 28:4390-4413. https://doi.org/10.1175/JCLI-D-14-00613.1

Kitoh A, Endo H, Krishna Kumar K et al (2013) Monsoons in a changing world: a regional perspective in a global context. J Geophys Res Atmos 118:3053-3065. https://doi.org/10.1002/ jgrd.50258

Knight JR, Folland CK, Scaife AA (2006) Climate impacts of the Atlantic multidecadal oscillation. Geophys Res Lett 33:L17706. https://doi.org/10.1029/2006GL026242

Koster RD, Dirmeyer PA, Guo Z et al (2004) Regions of Strong Coupling Between Soil Moisture and Precipitation. Science 80-(305):1138-1140. https://doi.org/10.1126/science.1100217

Lavaysse C, Flamant C, Janicot S et al (2009) Seasonal evolution of the West African heat low: a climatological perspective. Clim Dyn 33:313-330. https://doi.org/10.1007/s00382-009-0553-4

Lavaysse C, Flamant C, Evan A et al (2016) Recent climatological trend of the Saharan heat low and its impact on the West African climate. Clim Dyn 47:3479-3498. https://doi.org/10.1007/s0038 2-015-2847-z

Lawrence DM, Oleson KW, Flanner MG et al (2011) Parameterization improvements and functional and structural advances in Version 4 of the Community Land Model. J Adv Model Earth Syst. https ://doi.org/10.1029/2011MS00045

Lebel T, Ali A (2009) Recent trends in the Central and Western Sahel rainfall regime (1990-2007). J Hydrol 375:52-64. https://doi. org/10.1016/j.jhydrol.2008.11.030

Lélé MI, Leslie LM, Lamb PJ (2015) Analysis of low-level atmospheric moisture transport associated with the West African monsoon. J Clim 28:4414-4430. https://doi.org/10.1175/JCLI-D-14-00746.1

Losada T, Rodriguez-Fonseca B, Mohino E, Bader J, Janicot S, Mechoso CR (2012) Tropical SST and Sahel rainfall: A non-stationary relationship. Geophys Res Lett 39: L12705. https://doi. org/10.1029/2012GL052423

Ma J, Chadwick R, Seo K-H et al (2018) Responses of the tropical atmospheric circulation to climate change and connection to the 
hydrological cycle. Annu Rev Earth Planet Sci 46:549-580. https ://doi.org/10.1146/annurev-earth-082517-010102

Mariotti L, Diallo I, Coppola E, Giorgi F (2014) Seasonal and intraseasonal changes of African monsoon climates in 21st century CORDEX projections. Clim Change 125:53-65. https://doi. org/10.1007/s10584-014-1097-0

Martin ER, Thorncroft C (2014a) Sahel rainfall in multimodel CMIP5 decadal hindcasts. Geophys Res Lett 41:2169-2175. https://doi. org/10.1002/2014GL059338

Martin ER, Thorncroft CD (2014b) The impact of the AMO on the West African monsoon annual cycle. Q J R Meteorol Soc 140:3146. https://doi.org/10.1002/qj.2107

Meinshausen M, Smith SJ, Calvin K et al (2011) The RCP greenhouse gas concentrations and their extensions from 1765 to 2300 . Clim Change 109:213-241. https://doi.org/10.1007/s10584-011-0156-z

Mitchell JFB, Wilson CA, Cunnington WM (2007) On Co2 climate sensitivity and model dependence of results. Q J R Meteorol Soc 113:293-322. https://doi.org/10.1002/qj.49711347517

Mohino E, Janicot S, Bader J (2011) Sahel rainfall and decadal to multi-decadal sea surface temperature variability. Clim Dyn 37:419-440. https://doi.org/10.1007/s00382-010-0867-2

Monerie P-A, Fontaine B, Roucou P (2012) Expected future changes in the African monsoon between 2030 and 2070 using some CMIP3 and CMIP5 models under a medium-low RCP scenario. J Geophys Res Atmos. https://doi.org/10.1029/2012JD017510

Monerie P-A, Roucou P, Fontaine B (2013) Mid-century effects of climate change on African monsoon dynamics using the A1B emission scenario. Int J Climatol. https://doi.org/10.1002/joc.3476

Monerie P-A, Sanchez-Gomez E, Boé J (2016) On the range of future Sahel precipitation projections and the selection of a sub-sample of CMIP5 models for impact studies. Clim Dyn. https://doi. org/10.1007/s00382-016-3236-y

Monerie P-A, Sanchez-Gomez E, Pohl B et al (2017) Impact of internal variability on projections of Sahel precipitation change. Environ Res Lett 12:114003

Monerie P-A, Wainwright CM, Sidibe M, Akinsanola AA (2020) Model uncertainties in climate change impacts on Sahel precipitation in ensembles of CMIP5 and CMIP6 simulations. Clim Dyn 55:1385-1401. https://doi.org/10.1007/s00382-020-05332-0

Nicholson S (2005) On the question of the "recovery" of the rains in the West African Sahel. J Arid Environ 63:615-641. https://doi. org/10.1016/j.jaridenv.2005.03.004

Nicholson SE (2013) The West African Sahel: a review of recent studies on the rainfall regime and its interannual variability. ISRN Meteorol 2013:1-32. https://doi.org/10.1155/2013/453521

Nicholson SE, Palao IM (1993) A re-evaluation of rainfall variability in the sahel. Part I. Characteristics of rainfall fluctuations. Int J Climatol 13:371-389. https://doi.org/10.1002/joc.3370130403

Palmer TN (1986) Influence of the Atlantic, Pacific and Indian Oceans on Sahel rainfall. Nature 322:251

Panthou G, Lebel T, Vischel T et al (2018) Rainfall intensification in tropical semi-arid regions: the Sahelian case. Environ Res Lett 13:64013

Park J-Y, Bader J, Matei D (2015) Northern-hemispheric differential warming is the key to understanding the discrepancies in the projected Sahel rainfall. Nat Commun 6:5985

Roehrig R, Chauvin F, Lafore J-P (2011) 10-25-Day intraseasonal variability of convection over the Sahel: a role of the Saharan heat low and midlatitudes. J Clim 24:5863-5878. https://doi. org/10.1175/2011JCLI3960.1

Roehrig R, Bouniol D, Guichard F et al (2013) The present and future of the West African Monsoon: a process-oriented assessment of cmip5 simulations along the AMMA transect. J Clim 26:64716505. https://doi.org/10.1175/JCLI-D-12-00505.1

Rohde R, Muller A, Jacobsen R et al (2013) A new estimate of the average earth surface land temperature spanning 1753 to
2011. Geoinformatics Geostatistics An Overv. https://doi. org/10.4172/2327-4581.1000101

Rowell DP, Chadwick R (2018) Causes of the uncertainty in projections of tropical terrestrial rainfall change: east Africa. J Clim. https://doi.org/10.1175/JCLI-D-17-0830.1

Rowell DP, Folland CK, Maskell K et al (1992) Modelling the influence of global sea surface temperatures on the variability and predictability of seasonal Sahel rainfall. Geophys Res Lett 19:905-908. https://doi.org/10.1029/92GL00939

Sanogo S, Fink AH, Omotosho JA et al (2015) Spatio-temporal characteristics of the recent rainfall recovery in West Africa. Int $\mathbf{J}$ Climatol 35:4589-4605. https://doi.org/10.1002/joc.4309

Schneider U, Becker A, Finger P et al (2014) GPCC's new land surface precipitation climatology based on quality-controlled in situ data and its role in quantifying the global water cycle. Theor Appl Climatol 115:15-40. https://doi.org/10.1007/s00704-013-0860-x

Seth A, Rauscher SA, Biasutti M et al (2013) CMIP5 projected changes in the annual cycle of precipitation in monsoon regions. J Clim 26:7328-7351. https://doi.org/10.1175/JCLI-D-12-00726.1

Shekhar R, Boos WR (2017) Weakening and shifting of the Saharan shallow meridional circulation during wet years of the west African monsoon. J Clim 30:7399-7422. https://doi.org/10.1175/ JCLI-D-16-0696.1

Skinner CB, Ashfaq M, Diffenbaugh NS (2012) Influence of twentyfirst-century atmospheric and sea surface temperature forcing on west African climate. J Clim 25:527-542. https://doi. org/10.1175/2011JCLI4183.1

Smith R, Jones P, Briegleb B et al (2010) The parallel ocean program (POP) reference manual ocean component of the community climate system model (CCSM) and community earth system model (CESM). Rep LAUR 141:1-140 (01853)

Solomon S, Qin D, Manning M et al (2007) Climate change 2007-the physical science basis: working group I contribution to the fourth assessment report of the IPCC, vol 4. Cambridge university press

Stephens GL, Ellis TD (2008) Controls of global-mean precipitation increases in global warming GCM experiments. J Clim 21:61416155. https://doi.org/10.1175/2008JCLI2144.1

Taylor KE, Stouffer RJ, Meehl GA (2012) An overview of CMIP5 and the experiment design. Bull Am Meteorol Soc 93:485-498

Vecchi GA, Soden BJ (2007) Global Warming and the Weakening of the Tropical Circulation. J Clim 20:4316-4340. https://doi. org/10.1175/JCLI4258.1

Wang G, Alo CA (2012) Changes in precipitation seasonality in West Africa predicted by RegCM3 and the impact of dynamic vegetation feedback. Int J Geophys 2012:10. https://doi. org/10.1155/2012/597205

Whittleston D, Nicholson SE, Schlosser A, Entekhabi D (2017) Climate models lack jet-rainfall coupling over west Africa. J Clim 30:4625-4632. https://doi.org/10.1175/JCLI-D-16-0579.1

Willmott CJ, Matsuura K, Legates DR (2001) Terrestrial air temperature and precipitation: monthly and annual time series (19501999) (Version 1.02). Center for Climatic Research, Department of Geography, University of Delaware.

Yan Y, Lu R, Li C (2018) Relationship between the future projections of Sahel rainfall and the simulation biases of present south Asian and western north pacific rainfall in summer. J Clim 32:13271343. https://doi.org/10.1175/JCLI-D-17-0846.1

Publisher's Note Springer Nature remains neutral with regard to jurisdictional claims in published maps and institutional affiliations. 